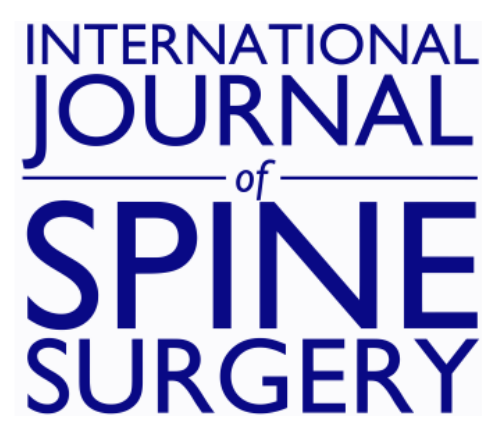

\title{
International Society for the Advancement of Spine Surgery Policy 2020 Update--Minimally Invasive Surgical Sacroiliac Joint Fusion (for Chronic Sacroiliac Joint Pain): Coverage Indications, Limitations, and Medical Necessity
}

MORGAN LORIO, RICHARD KUBE and ALI ARAGHI

Int J Spine Surg 2020, 14 (6) 860-895

doi: https://doi.org/10.14444/7156

http://ijssurgery.com/content/14/6/860

This information is current as of April 25, 2023.

Email Alerts Receive free email-alerts when new articles cite this article. Sign up at:

http://ijssurgery.com/alerts 


\title{
International Society for the Advancement of Spine Surgery Policy 2020 Update-Minimally Invasive Surgical Sacroiliac Joint Fusion (for Chronic Sacroiliac Joint Pain): Coverage Indications, Limitations, and Medical Necessity
}

\author{
MORGAN LORIO, MD, FACS, ${ }^{1}$ RICHARD KUBE, MD, ${ }^{2}$ ALI ARAGHI, DO ${ }^{3}$ \\ ${ }^{1}$ Advanced Orthopedics, Altamonte Springs, Florida, ${ }^{2}$ Prairie Spine \& Pain Institute, Peoria, Illinois, ${ }^{3}$ The CORE Institute, Sun City West, Arizona
}

\begin{abstract}
The index 2014 International Society for the Advancement of Spine Surgery Policy Statement-Minimally Invasive Surgical Sacroiliac Joint Fusion - was generated out of necessity to provide an International Classification of Diseases, Ninth Revision (ICD-9)-based background and emphasize tools to ensure correct diagnosis. A timely ICD-10-based 2016 update provided a granular threshold selection with improved level of evidence and a more robust and relevant database (Appendix Table A1). As procedures and treatment options have evolved, this 2020 update reviews and analyzes the expanding evidence base and provides guidance relating to differences between the lateral and dorsal surgical procedures for minimally invasive surgical sacroiliac joint fusion.
\end{abstract}

Testing \& Regulatory Affairs

Keywords: sacroiliac joint, minimally invasive surgery, pelvis, diagnosis

\section{OVERVIEW OF SACROILIAC JOINT ANATOMY, PAIN ETIOLOGY AND EPIDEMIOLOGY, DIAGNOSIS, AND NONSURGICAL INTERVENTIONS}

\section{Anatomy and Innervation}

The sacroiliac joints (SIJs) are diarthrodial articulations of the sacrum and ilium with a joint capsule, synovial membrane, and opposing articular surfaces covered in hyaline cartilage. ${ }^{1}$ The SIJ serves as the biomechanical mediator between the spine and pelvis. ${ }^{2,3}$ The subchondral bone, capsule, and surrounding ligaments of the SIJ are innervated by spinal nerves. ${ }^{4}$ The joint moves (allowing both translational motion and rotation of the sacrum on the ilium), albeit only a small amount. SIJ pain is not correlated to the amount of joint motion. ${ }^{5}$ SIJ dysfunction or pain may be associated with altered laxity or stiffness of the SIJ, with increased or decreased joint translations, a new joint position, and/or exaggerated or reduced joint compression. ${ }^{6}$ The SIJ complex consists of an anterior portion (the articular portion of the joint) and a posterior extraarticular portion made up of the interosseous and dorsal ligamentous structures. The anterior portion of the joint is innervated anteriorly via branches of the ventral rami of the spinal nerves and ultimately from branches of the gluteal nerves, the obturator nerve, and the lumbosacral trunks $s^{4,7-11}$ and posteriorly by the lateral branches of the S1-S3 dorsal rami and fibers of the L5 dorsal ramus in some cases. $^{7,10-17}$ Pain from the SIJ complex may arise from the posterior extra-articular elements in addition to, or separate from, the intra-articular elements. ${ }^{18}$ Frequent sources of extra-articular pain are ligamentous and muscular injuries, and enthesopathy. ${ }^{19}$

\section{SIJ Pain Etiology and Epidemiology}

SIJ pain is an important cause of acute and chronic low back pain. In some studies, the proportion of chronic low back pain attributable to the SIJ is $15 \%-30 \%{ }^{20-24} \mathrm{SIJ}$ dysfunction or pain is frequently (up to $40 \%$ in some studies) implicated in patients with new or ongoing low back pain after lumbar fusion. ${ }^{25-28}$ Lumbar fusion is likely a risk factor for SIJ pain as biomechanical studies have shown significant stress transfer from the lumbar spine to the SIJ after 1- and 2-level lumbar fusion. ${ }^{29}$ Adjacent-segment degeneration after lumbar fusion 
is well described and well accepted. ${ }^{30,31}$ Several authors have documented the association of SIJ (the adjacent segment caudal to a lumbosacral fusion) pain with multilevel lumbar fusion. ${ }^{32-36}$ Unoki et $\mathrm{al}^{37}$ have shown increased incidence of postoperative SIJ pain with increased number of spinal levels fused. Sagittal alignment is also known to affect adjacent-segment degeneration after spinal fusion. ${ }^{38}$ Several authors have examined lumbar sagittal balance as a contributor to post-lumbar fusion SIJ pain suggesting that failure to restore lumbar lordosis (leaving the patient with a residual pelvic incidence-lumbar lordosis mismatch) is associated with post-lumbar fusion SIJ pain. ${ }^{39-41}$

\section{Impact of SIJ Pain}

The spectrum of pain and disability from SIJ dysfunction is wide. Patients may be affected mildly or may have substantial functional impairment (eg, cannot sit or stand for more than 5 minutes, cannot perform normal activities of daily living, cannot walk up or down stairs, may require a wheelchair). Patients with chronic SIJ dysfunction seeking surgical treatment have marked impairment of quality of life (QOL), ${ }^{42}$ similar to that observed in other spinal conditions commonly treated surgical$1 \mathrm{y} .{ }^{43}$

\section{SIJ Pain Diagnosis}

Convergence of the sensory pathway from the hip, the SIJ, and the lumbar spine may result in overlap of pain patterns from dysfunction of these structures. As such, proper SIJ pain diagnosis is key to appropriate patient management.

SIJ pain diagnosis is typically accomplished via a clinical diagnostic algorithm involving history, physical exam, diagnostic block, and ruling out other pain contributors. Patients with SIJ pain typically report pain in the buttock(s), with possible radiation into the groin or upper legs. Position and range of motion testing of the SIJ are not reliable. ${ }^{44-47}$ Specific physical examination tests that stress the SIJ (eg, distraction test, compression test, thigh thrust, Flexion ABduction External Rotation [FABER aka Patrick] test, Gaenslen maneuver) are typically performed in the physician's office; in combination, these tests are thought to be predictive of a positive response to intra-articular SIJ block and likely indicative of SIJ pain. ${ }^{48-51}$ Other authors have presented conflicting data and results stating physical exam maneuvers to identify intra-articular
SIJ pain did not demonstrate diagnostic value when compared with the reference standard of an intraarticular anesthetic block. ${ }^{22,45,52}$ With an increasing number of positive physical examination maneuvers, the diagnosis of SIJ pain is more likely. ${ }^{53} \mathrm{~A}$ recent systematic review determined there was significant evidence to constitute a clinical diagnostic rule for SIJ pain based upon 3 of 5 positive tests. ${ }^{54}$

Imaging of the SIJ may be helpful in cases of inflammatory sacroiliitis ${ }^{55}$ and acute trauma. However, no specific imaging modality has demonstrated acceptable sensitivity and specificity in the diagnosis of noninflammatory, nontraumatic SIJ pain, ${ }^{2,19,56}$ including plain radiographs,${ }^{57}$ computed tomography $(\mathrm{CT}),{ }^{58}$ magnetic resonance imaging, ${ }^{59}$ and radionucleotide studies. ${ }^{60,61}$ In many cases, imaging may demonstrate nonspecific findings in the SIJ. ${ }^{62-64}$ Pelvic and spine imaging is used to ensure that the patient does not have alternative diagnoses that could mimic SIJ pain (eg, hip osteoarthritis, occasionally L5-S1 spine degeneration).

The diagnosis of SIJ pain is confirmed by performing an image-guided percutaneous intraarticular SIJ block with local anesthetic (eg, lidocaine). The SIJ has a large surface area but has a very small joint capacity which ranges from 0.8 to $2.5 \mathrm{~mL}$ in asymptomatic individuals, and from 1.0 to $2.5 \mathrm{~mL}$ in symptomatic individuals. ${ }^{65,66}$ It is generally advised to inject no more than $2.5 \mathrm{~mL}$ during an intra-articular diagnostic injection. ${ }^{67,68}$ Extravasation of injectate (local anesthetic) onto nearby neural structures theoretically compromises the specificity of the diagnostic injection. ${ }^{16}$ Periarticular SIJ block ${ }^{69,70}$ is not considered a reference standard for the diagnosis of pain coming from the articular SIJ. A periarticular block will likely anesthetize soft tissues in the dorsal aspect of the SIJ and sacrum. Pain arising from these soft tissues may or may not respond to surgical fusion of the SIJ. An acute reduction in typical pain following an intra-articular block indicates a positive test, suggesting that the injected joint is a pain generator. A study of patients undergoing blinded injection of saline or local anesthetic showed markedly high responses to the latter, validating the test. ${ }^{71}$

Occasionally, bilateral SIJ pain can occur. Diagnosis of bilateral SIJ pain should be made on the basis of typical history (bilateral symptoms), physical examination showing positive responses to SIJ-stressing maneuvers bilaterally, and bilateral 
acute pain relief upon bilateral, image-guided SIJ block.

\section{Higher Response to Diagnostic Block Does Not Predict Higher Response to Definitive Treatment} While a marked response to SIJ block might reassure the physician that treatment will produce larger responses to anatomic-based intervention, published data suggest little, if any, relationship. In 2 large prospective clinical trials of lateral transiliac MIS SIJ fusion (SIJF) with transfixing devices, patients with suspected SIJ pain were included only if intra-articular SIJ block resulted in a $50 \%$ or greater acute pain relief within 60 minutes after the block. The amount of improvement at 12 and 24 months after SIJF was unrelated to the amount of acute pain relief during the block. ${ }^{72}$ In a retrospective analysis of predictors of outcome success after radiofrequency (RF) ablation of lateral branches of the sacral nerve roots in patients with SIJ pain, no relationship was observed between response to lateral branch block or SIJ anesthesia and response to RF ablation. ${ }^{73}$ Randomized trials of RF ablation of lateral branches of the sacral nerve roots excluded patients with $<75 \%$ pain reduction after lateralbranch block ( 1 block in Cohen et $\mathrm{al}^{74}$ and 2 blocks in Patel et $\mathrm{al}^{75}$ ), leaving open the question of whether the selected threshold was appropriate. Application of an overly stringent selection criteria (ie, 75\% response) has no basis in evidence and is likely to result in the withholding of a beneficial procedure from a substantial number of patients with significant pain and functional impairment. ${ }^{72}$

\section{Nonsurgical Treatment}

Multiple nonsurgical treatments for SIJ pain are available, including pain medications (eg, nonsteroidal anti-inflammatory drugs [NSAIDs]), physical therapy (PT), steroid injections into the SIJ, and RF ablation of the sacral nerves. NSAIDs in combination with icing and activity modification may be helpful in reducing pain in acute or subacute SIJ pain. ${ }^{76}$ However, NSAIDS have not been shown to impact the underlying disease process. Opioids have not been shown to be a safe and effective treatment for chronic SIJ pain and addiction remains an important public health concern.

The effectiveness of PT for treating chronic SIJ dysfunction and pain has not been demonstrated. There is a paucity of high-level literature secondary to the great variability in the functional biomechan- ical deficits in patients with SIJ pain, and that standard practice is to apply more than one form of treatment at a time. In addition, much of the literature evaluates patients with acute or subacute SIJ pain. A significant portion of this patient population would be expected to improve with time, with or without intervention. Generally, the approach to therapeutic exercise is linked to balancing muscle length, strength, and appropriate motor control in order to efficiently absorb and transmit force from the ilium to the sacrum. ${ }^{77} \mathrm{PT}$ treatments (eg, exercise, manipulation) may provide benefit in some patients and are a reasonable option with few risks. ${ }^{19,78}$ It is reasonable to prescribe a short course (4-6 weeks) of individualized, supervised therapeutic exercises focused on strengthening of the core muscles (local stabilizers) progressing to strengthening of the global stabilizers as tolerated. ${ }^{79,80}$ Exercise programs should be individually tailored based on clinical findings, physical capacity, and anticipated compliance. It is not reasonable to continue with a therapeutic exercise program if it is painful for the patient or in cases where the patient fails to improve after a reasonable course of treatment (4-6 weeks).

Therapeutic exercise in SIJ pain patients is typically focused on core strengthening. One randomized, controlled trial (RCT) performed in peripartum women (acute and subacute SIJ pain onset during pregnancy or within 3 weeks of delivery) showed significant improvement in pain and function at 12 months. The therapy program consisted of an individualized, supervised program of stabilization exercises lasting 20 weeks. ${ }^{80} \mathrm{~A}$ second RCT in a similar patient population showed minimal improvement in pain or function with an 8week program consisting of stabilization exercises that were not individualized and not supervised. ${ }^{81} \mathrm{~A}$ study comparing 4 weeks of therapeutic exercise to laser treatment in patients with acute and subacute SIJ pain $(<3$ months duration) showed improvements in pain and function at 12 months in the exercise group. ${ }^{82}$ Another small study (51 patients with SIJ-related leg pain [duration $>4$ weeks but less than 1 year] without confirmatory diagnostic block) compared therapeutic exercise (6 weeks) to manual PT and steroid injection. ${ }^{83}$ Only $20 \%$ of the patients in the PT cohort had improvement that met minimal clinically important difference (MCID) (2-point improvement on visual analog scale [VAS]) at 12 weeks. In the nonsurgical treatment cohorts of the 
iFuse Implant System (SI-BONE, Inc) RCTs, the percentage of patients (all of whom were symptomatic for at least 6 months) that met MCID for pain improvement at 6 months were $24 \%$ in INSITE (Investigation of Sacroiliac Fusion Treatment) ${ }^{84}$ (mean number of PT visits: 14 ) and $22 \%$ in iMIA (iFuse Implant Minimally Invasive Arthrodesis) ${ }^{85}$ (mean number of PT visits: 26). In the large multicenter MINT (Cost-Effectiveness of Minimal Interventional Procedures for Patients with Chronic Low Back Pain) RCT, patients with chronic SIJ pain were randomized to PT (3-month standardized exercise program and psychological support if needed) versus RF ablation. Fifty-five percent of the PT group patients had at least a 2-point improvement on VAS compared to $58 \%$ of the RF ablation group at 12 months. ${ }^{86}$

Manual medicine techniques (manual therapy, osteopathic manual treatment, chiropractic adjustments) are often part of the treatment of SIJ pain. Several poorly controlled studies of these treatments have demonstrated clinical improvement of SIJ pain. ${ }^{87-90}$ In a recent review of PT interventions, Al-Subahi et $\mathrm{al}^{91}$ identified 4 studies that met inclusion criteria and concluded there is some evidence that SIJ manipulation may lead to improvements in pain and function. These studies suffered from small sample size, lack of a control group or use of an unproven treatment as a control, or from inclusion based upon unreliable physical examination tests. ${ }^{92-95}$ SIJ bony asymmetries have been clinically shown in uncontrolled studies to resolve with manipulation. ${ }^{90,96}$ SIJ position and range of motion testing has been shown in wellcontrolled studies to be unreliable. ${ }^{44-47}$ Tullberg et al, ${ }^{97}$ using radio stereophotogrammetric analysis, showed no change in SIJ bony position after SIJ manipulation and Dreyfuss et $\mathrm{al}^{45}$ showed no significant correlation between "joint motion" and response to intra-articular injection of local anesthetic. If an SIJ appears to require recurrent joint mobilization, a significant muscle imbalance may still exist or the patient may have joint hypermobility as a result of conditions such as Ehlers-Danlos syndrome. Some of this may be related to patient compliance or an inadequate neuromotor control and strength-directed program, or may be related to the patient's inherent collagen makeup that allows increased joint mobility and/or tissue laxity. Caution should be used with repetitive manipulation in the latter group. ${ }^{77}$ In spite of the low level of evidence to support manipulation and other manual treatments, the low risks of these interventions warrant consideration by trained professionals. ${ }^{98}$

Intra-articular SIJ steroid injections are commonly provided interventions worldwide. ${ }^{99,100}$ There is no high-level evidence supporting the shortor long-term effectiveness of this treatment option. Three pragmatic RCTs of SIJ steroid injection randomized against radiofrequency (RF) ablation have been published. ${ }^{101-103}$ None of these studies demonstrated improvement in pain or function beyond 1 month with injections. Another study of SIJ steroid injection versus prolotherapy showed no significant improvement in the steroid cohort beyond 2 weeks. ${ }^{104}$ In the absence of definitive data supporting corticosteroid injections as superior to placebo, the value of trials with corticosteroid injections as an active control group is questionable. Repeated steroid injections have shown association with accelerated cartilage degeneration in the hip and the knee. ${ }^{105,106}$ The cost-effectiveness of SIJ steroid injections has not been determined. No studies have demonstrated long-term pain relief, nor have studies confirmed the benefit of repeating this procedure multiple times. Other interventions to treat pain arising from the SIJ complex include prolotherapy and injection of platelet-rich plasma or other substances. There is no high-level literature to support these other interventions.

RF ablation is another commonly performed intervention to treat pain arising from the SIJ complex. Four explanatory randomized trials (RF ablation versus sham) have been published. Two studies showed that RF ablation of lateral branches of sacral nerve roots can temporarily reduce SIJ pain. ${ }^{74,75}$ One-year follow-up from one RF ablation randomized trial showed modest pain reduction. ${ }^{107}$ Mehta et $a 1,{ }^{108}$ in a small trial $(n=30)$ of RF ablation strip lesioning versus sham, showed significant improvement in VAS and EuroQOL-5D scores at 3 months. A more recent study of heated RF ablation versus sham demonstrated no significant difference in pain level or patient satisfaction at 1 or 3 months. ${ }^{109}$ There are 3 pragmatic RCTs of RF ablation randomized against SIJ steroid injection. Salman et al ${ }^{101}$ showed $53 \%$ of patients had at least $50 \%$ pain improvement with heated RF ablation at 6 months. Cánovas et $\mathrm{al}^{103}$ showed modest improvement (2 points on VAS at 12 months with bipolar palisade) and better results (4 points VAS improvement at 12 months) with a 
modified bipolar palisade technique. In a small series ( 30 patients), Dutta et al ${ }^{102}$ showed improvement in VAS in the RF ablation group of 3.8 points at 6 months with pulsed RF ablation. In a much larger study of SIJ RF ablation randomized against PT, the authors demonstrated no significant differences in pain level or patient satisfaction at 3, 6, 9, or 12 months. ${ }^{86} \mathrm{RF}$ ablation was not considered to be cost-effective from a societal perspective for patients with chronic pain originating from the SIJ in the Dutch healthcare setting. ${ }^{110}$ Interpretation of the RF ablation literature is limited by variability in patient selection criteria, the specific nerves targeted for ablation, and the types of RF ablation technology and technique utilized. ${ }^{18}$

\section{COVERAGE RATIONALE FOR OPEN AND MIS SIJ FUSION}

Given the absence of published outcomes data supporting long-term pain relief from nonsurgical treatment, patients with a diagnosis of chronic SIJ pain who experience pain for a minimum of 6 months, and who do not respond to an appropriate course of nonsurgical treatment, may be considered for SIJF.

\section{Open SIJF Procedures}

Open fusion of the SIJ, first reported in the early 1900 s, ${ }^{111}$ can provide pain relief but recovery times are long and complication rates may be high. ${ }^{112-117}$ Intraoperative times, bleeding, and hospital length of stay are more prominent compared to MIS SIJF, ${ }^{117-120}$ and recovery times are long and may require prolonged postoperative rehabilitation. The open surgical procedure, whether from an anterior, a posterior, or a lateral approach, requires a large incision ( $8 \mathrm{~cm}$ or greater) and extensive surgical dissection. Open procedures are associated with increased surgical time and correspondingly increased patient morbidity. In certain cases, such as acute trauma, tumor, infection, or for SIJF in conjunction with pelvic fixation in spinal deformity surgery, open SIJF is indicated.

\section{Anterior Approach}

The anterior surgical approach to the SIJ was described in 1941. ${ }^{121}$ The anterior approach to the SIJ for open reduction and internal fixation in cases of SIJ trauma was popularized in the 1980s. ${ }^{122,123}$ More recently, the anterior approach has been utilized for elective SIJF and several series have been reported. ${ }^{124-127}$ Most series describe a surgical approach that follows the anterior iliac crest deep to the iliacus muscle (subiliacus approach). This approach is associated with significant morbidity including possible injuries to the vascular, gastrointestinal, and genitourinary structures, L5 nerve root, and lateral femoral cutaneous nerve. Postoperative hip flexor weakness has also been described. ${ }^{128}$ Murakami et al ${ }^{129}$ have described a para-rectus retroperitoneal anterior approach to the SIJ with less patient morbidity. After the joint is accessed, the anterior joint capsule is removed and the articular SIJ is debrided with a burr and curettes. The articular joint is bone-grafted and the joint is stabilized with a short plate and multiple screws. The size of the plate is limited by the local bony anatomy and close proximity of the L5 nerve root.

\section{Lateral Approach}

The lateral approach was described by SmithPetersen and colleagues in the 1920s. ${ }^{130-132}$ In this approach, the gluteus musculature is elevated from the lateral aspect of the ilium and a bone window is created through the ilium providing access to the SIJ. The interosseous ligament and the articular cartilage are debrided, the joint is grafted and the bone window is replaced. Several variations of the procedure have been described. ${ }^{116,133,134}$ Concurrent permanent fixation of the SIJ with screws, either from lateral or posterior approach, is described by most authors.

\section{Posterior Approach}

The posterior approach to the SIJ was first described in 1908. ${ }^{111}$ Early reports described debridement of posterior soft tissues and grafting of the dorsal recess. Postoperatively the patient was placed into a hip spica cast for several months to immobilize the joint. As fixation methods improved, a variety of posterior fusion procedures were described including application of posterior bars and iliac plates. ${ }^{113,135}$ The most recent description of the open posterior procedure describes an osteotomy of the medial aspect of the posterior iliac crest to allow surgical access to the articular SIJ. This open procedure includes excision or debridement of the dorsal ligaments, dorsal joint capsule, interosseous ligament, and osteoclasis of the articular SIJ cartilaginous surfaces, which lie ventral to the ligamentous portion of the joint. Surgical access to these structures is not possible without an osteotomy of 
the overlying iliac crest. Bone graft and spacers or cages are typically placed into the joint. The joint is then stabilized with fixation that includes a pedicle screw into the ilium, and a pedicle screw into the sacrum connected with a spinal rod. ${ }^{114,117}$

Open posterior SIJF is frequently performed as part of long spinal deformity fusion procedures that include pelvic fixation (sacroalar iliac [S2AI] or iliac screws or bolts). ${ }^{136}$ As described below, SIJF has been proposed in response to concerns of implant failure and postoperative SIJ pain. Long spinal fusion with pelvic fixation is associated with an elevated risk of new-onset SIJ pain ${ }^{32,33,35,36}$ and increased incidence of SIJ pain and an increased incidence of SIJ pain is correlated with increased number of levels fused. ${ }^{37}$ Pelvic fixation with both S2AI and iliac screws is associated with a significant risk of screw loosening $(0 \%-39 \%)$ and screw failure $(0 \%-24 \%) .{ }^{137}$ Pelvic fixation likely alters the biomechanics of the SIJ but clinical implications have not been defined. ${ }^{1}$ Continued SIJ motion after pelvic fixation may contribute to screw loosening and/or failure ${ }^{138}$ and may also contribute to postoperative lower back pain. ${ }^{139}$ Screw loosening is common even with solid fusion at L5-S1, indicating that the SIJ remains mobile. ${ }^{140,141}$ S2AI screws have been shown to violate the articular cartilage of the SI joint in $40 \%$ of cases. ${ }^{142}$ Some surgeons now advocate for 2 points of fixation in conjunction with SIJF in pelvic fixation cases in order to minimize SIJ rotation. ${ }^{143-145}$ Recent biomechanical studies have shown that placement of titanium triangular implants (TTI) in conjunction with an S2AI screw decreases SIJ motion by $30 \%$ and lowers strain on the adjacent $\mathrm{S} 1$ and S2AI screws. ${ }^{146}$ This approach is currently under study.

\section{MIS SIJF Procedures}

MIS principles and techniques have been applied to SIJF. New devices allow stabilization and fusion of the SIJ with small incisions and minimal soft tissue damage. As with other MIS procedures, MIS SIJF has shown decreased operative time, decreased blood loss, and decreased hospital stay compared to the open procedure. ${ }^{117,119,120}$ SIJF is most commonly performed via an MIS procedure. ${ }^{147}$ Two different MIS SIJF procedures have been described.

\section{Lateral Transiliac MIS Procedure}

The lateral transiliac MIS procedure involves placement of devices that transfix the SIJ (ie, a device that traverses the ilium and the SIJ and ends in the sacrum). The surgical approach is from the lateral or posterolateral ilium with device placement through the ilium, across the SIJ, and into the sacrum. Approximately 25 devices are currently cleared by the US Food and Drug Administration (FDA) for this procedure ${ }^{*}$ and the FDA indication statement typically describes use in patients with chronic SIJ pain and/or disruption (eg, related to trauma or overuse) and degenerative sacroiliitis (osteoarthritic degeneration).

\section{Posterior (Dorsal) MIS Procedure}

The posterior (dorsal) MIS procedure involves placement of bone allograft products or devices into the ligamentous portion of the joint via dissection of the multifidus muscle and removal of a portion of the ligaments covering the outer posterior surface of the joint. The stabilization strategy with these products is ligamentotaxis and the fusion strategy is distraction arthrodesis. The majority of the products used for this procedure are unclassified allograft bone products (human cell and tissue products) and therefore do not carry an indication statement specific to SIJF. There are 2 FDA-cleared medical devices used for posterior MIS procedures: Catamaran SIJ Fixation System (Tenon Medical, Inc) ${ }^{\dagger}$ and NADIA (Ilion Medical, Inc) ${ }^{\ddagger}$

\section{LATERAL TRANSILIAC MIS PROCEDURES}

\section{Procedure Description}

Lateral transiliac MIS SIJF has become progressively more common and more accepted ${ }^{147}$ as the physician community becomes more aware of the condition and better versed in the diagnosis and management (both surgical and nonsurgical) of the

\footnotetext{
*FDA 510(k) Premarket Notification Database: K080398and K092375 (accessed 9/30/20). Companies marketing lateral SIJ devices: SI-BONE, Medtronic, Globus Medical, Xtant, Surgalign (formerly RTI), Alevio, CoreLink, Orthofix/ Medical Designs, Camber Medical, Zimmer Biomet, Captiva Spine, Coorstek, Life Spine, SICage, SpineFrontier, SI-Technology, Medacta, Frontier Devices, L\&K Biomed, Zavation, Huvexel.

†https://www.tenonmed.com/catamaran, https://www. accessdata.fda.gov/scripts/cdrh/cfdocs/cfpmn/pmn $\mathrm{cfm}$ ?ID $=\mathrm{K} 180818$

\#http://ilionmedical.com/, https://www.accessdata.fda.gov/ scripts/cdrh/cfdocs/cfpmn/pmn.cfm?ID=K 190580
} 
condition. Nearly all such procedures follow the lateral trajectory approach initially published by Routt et $\mathrm{al}^{148}$ for use in iliosacral fixation to treat traumatic injuries of the posterior pelvic ring.

Several reports describe lateral SIJF using iliosacral fixation screws with supplemental bone grafting from posterior or lateral approaches. ${ }^{116,149}$ In the United Kingdom, Mohanty popularized lateral MIS SIJF using a cage filled with bone in an effort to avoid supplemental bone grafting and thus lessen the morbidity and cost of the procedure. Three different series describe use of a lateral approach with placement of these hollow modular anchor cages from Aesculap. ${ }^{150-152}$ (This device is not FDA-cleared for use in the United States for this indication.)

In 2008, SI-BONE, Inc, received FDA clearance to market a TTI with a porous surface for SIJF. Subsequent to this, at least 25 different lateral transiliac transfixing devices have received FDA clearance for lateral MIS SIJF. ${ }^{\S}$ The clinical evidence base for use of these devices has grown substantially over the past decade; however, most high-level clinical evidence supporting the safety, effectiveness, durability, and economic benefit of lateral MIS SIJF is derived from use of iFuse. Physician work and resource utilization studies have been published on the lateral MIS SIJF procedure. $^{153-155}$

\section{Clinical Evidence}

Clinical evidence for lateral transiliac MIS SIJF is now substantial and includes 2 RCTs and 5 multicenter prospective studies. These studies provide substantial evidence that lateral transiliac MIS SIJF with placement of lateral transfixing devices is safe and effective. Studies demonstrate consistent improvements in pain, function, and QOL. In both randomized trials, pain relief, disability reduction, and improvement in QOL were markedly higher in SIJF subjects compared to nonsurgically treated subjects. Results of lateral transiliac MIS SIJF with transfixing TTIs are consistent across patient

\footnotetext{
${ }^{\S}$ FDA 510(k) Premarket Notification Database: K080398and K092375 (accessed 9/30/20). Companies marketing lateral SI joint devices: SI-BONE, Medtronic, Globus Medical, Xtant, RTI, Alevio, CoreLink, Orthofix/Medical Designs, Camber Medical, Zimmer Biomet, Captiva Spine, Coorstek, Life Spine, SICage, SpineFrontier, SI-Technology, Medacta, Frontier Devices, L\&K Biomed, Zavation, Huvexel.
}

populations and geographies, and preliminary data from non-TTI lateral transfixing devices appear to provide similar responses (Figure 1 and Figure 2).

\section{Level I Studies Summary}

Two prospective, multicenter RCTs have yielded numerous (Level I) published studies evaluating lateral transiliac MIS SIJF using TTI (iFuse Implant System, SI-BONE, Inc). These studies demonstrate the immediate and sustained pain relief experienced by patients treated with lateral transiliac MIS SIJF.

INSITE. In the INSITE trial, a multicenter, prospective RCT conducted in the United States, ${ }^{156}$ subjects treated with iFuse had early (1 month) and sustained (24 months) improvement in pain and function. VAS SIJ pain improved from 82.3 to 26.1 (55.8 points, $P<.0001$ ). Mean changes in the nonsurgical group were not clinically significant (mean 12 points by month 6) and many subjects crossed over to surgical treatment (which was successful in most cases). Similarly, in the SIJF group, mean Oswestry Disability Index (ODI) scores decreased from 57.2 to 28.5 (28.5 points, $P$ $<.0001)$. The 6-month improvement in ODI in the nonsurgical group was 4.6 points (substantially less than the 15-point MCID threshold used in the study). Similar rapid and sustained clinically important improvements were seen in QOL measures (SF-36 PCS [Short Form-36 Physical Component Summary] and EuroQOL-5D [European Quality of Life Scale-Five Dimension]) in the surgical group. There was no statistical difference in number of adverse events per subject between the iFuse and the nonsurgical groups. There were 3 revision surgeries $(3 \%)$ within the 24-month follow-up.

iMIA. In iMIA, a multicenter, prospective RCT conducted in Europe, ${ }^{157}$ similar results were seen as in the INSITE trial. The 2-year results were published in The Journal of Bone and Joint Surgery in 2019. Mean VAS low back pain improvement was 45 points in subjects undergoing SIJF with iFuse implants and 11 points for those treated with conservative management (primarily PT). Disability scores (ODI) improved by a mean of 26 points in the surgical group versus 8 points in the conservative management group. Statistically significant and clinically important improvements were also documented in VAS leg pain, EQ-5D TTO, and Zung Depression score. Patient-reported improvement in 

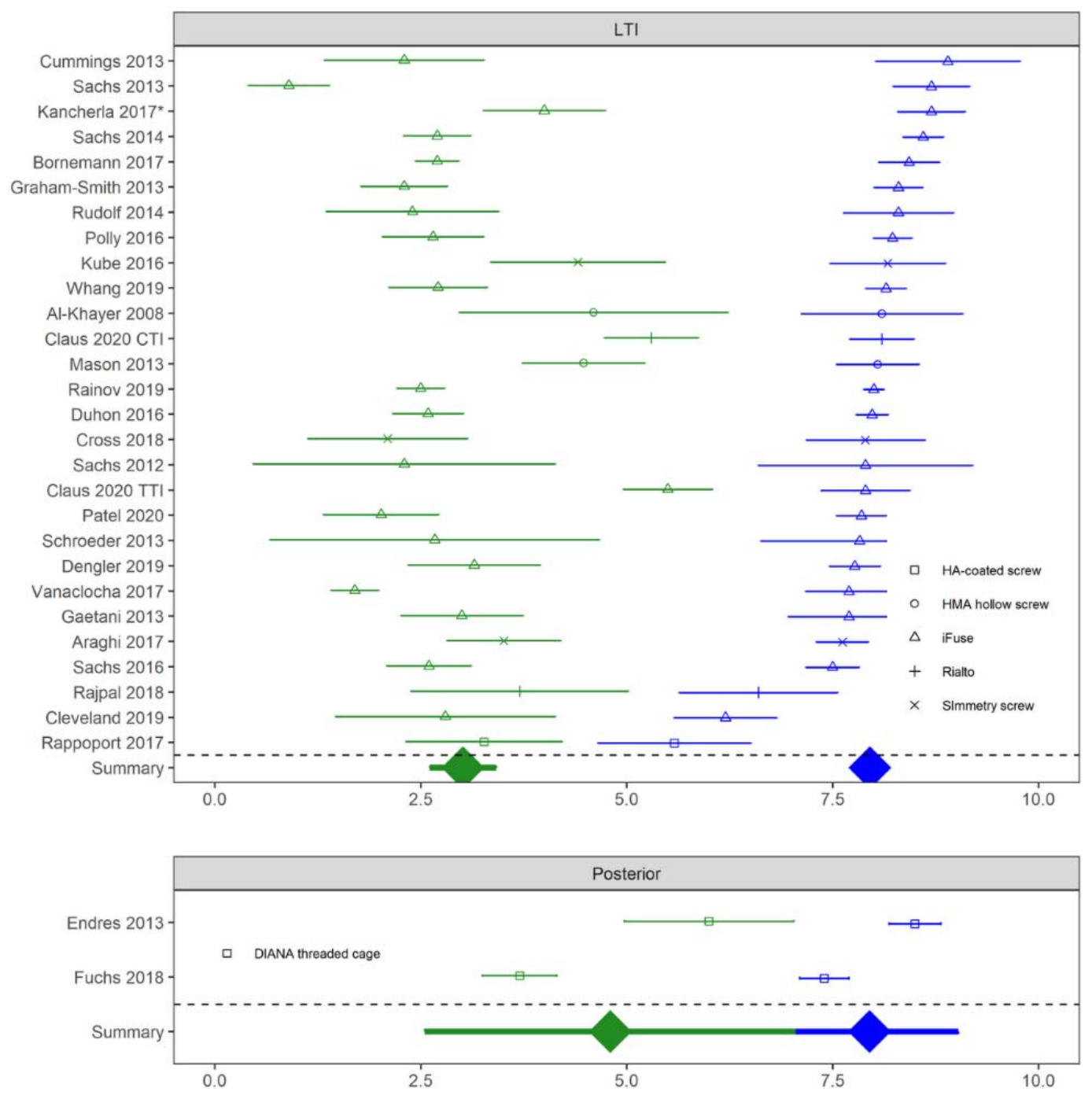

Figure 1. Baseline (blue) and last follow-up (green) visual analog scale or numeric rating scale sacroiliac joint (SIJ) pain scores in cohorts of patients treated with lateral transiliac (LTI) SIJ fusion (SIJF) or posterior SIJF. Horizontal bracketed bars denote confidence limit. Device type shown by shape. Kancherla is primarily titanium triangular implants but includes a small number of cases with a screw. CTI indicates cylindrical titanium implant.

walking distance and improvement in work status were also documented.

\section{Level II Studies Summary}

Five prospective, multicenter (level II) studies evaluating lateral transiliac MIS SIJF using 3 different lateral transfixing devices have been published. These studies confirm the results of the level I studies in different practice settings, and confirm the homogeneity of the outcomes of the lateral transiliac MIS SIJF procedure.

Sacroiliac Joint Fusion with iFuse Implant System (SIFI). In SIFI, a prospective, multicenter trial conducted in the United States, 172 subjects underwent SIJF with TTI (iFuse Implant System). Mean SIJ pain improved from 79.8 to 26.0 at 24 months. ${ }^{158}$ Mean ODI improved from 55.2 to 30.9 at 24 months. The SIJ revision rate was $4.7 \%(8$ subjects) by 24 months.

Long Term Outcomes from INSITE and SIFI (LOIS). In LOIS, subjects participating in the above-described SIFI and INSITE studies agreed to long-term follow-up. ${ }^{159}$ At year 5, improvements from baseline in pain, disability and QOL were durable. From baseline to 5 years there was a $54-$ point mean improvement in SIJ pain, a 26-point mean improvement in ODI, and a $0.29(0-1$ scale) improvement in EuroQOL-5D scores. There was no deterioration of results between year 2 and year 5 . A total of 3 of 103 subjects $(3 \%)$ had a surgical revision by 5 years. Independent radiographic analysis with thin-cut CT scans at 5 years demon- 

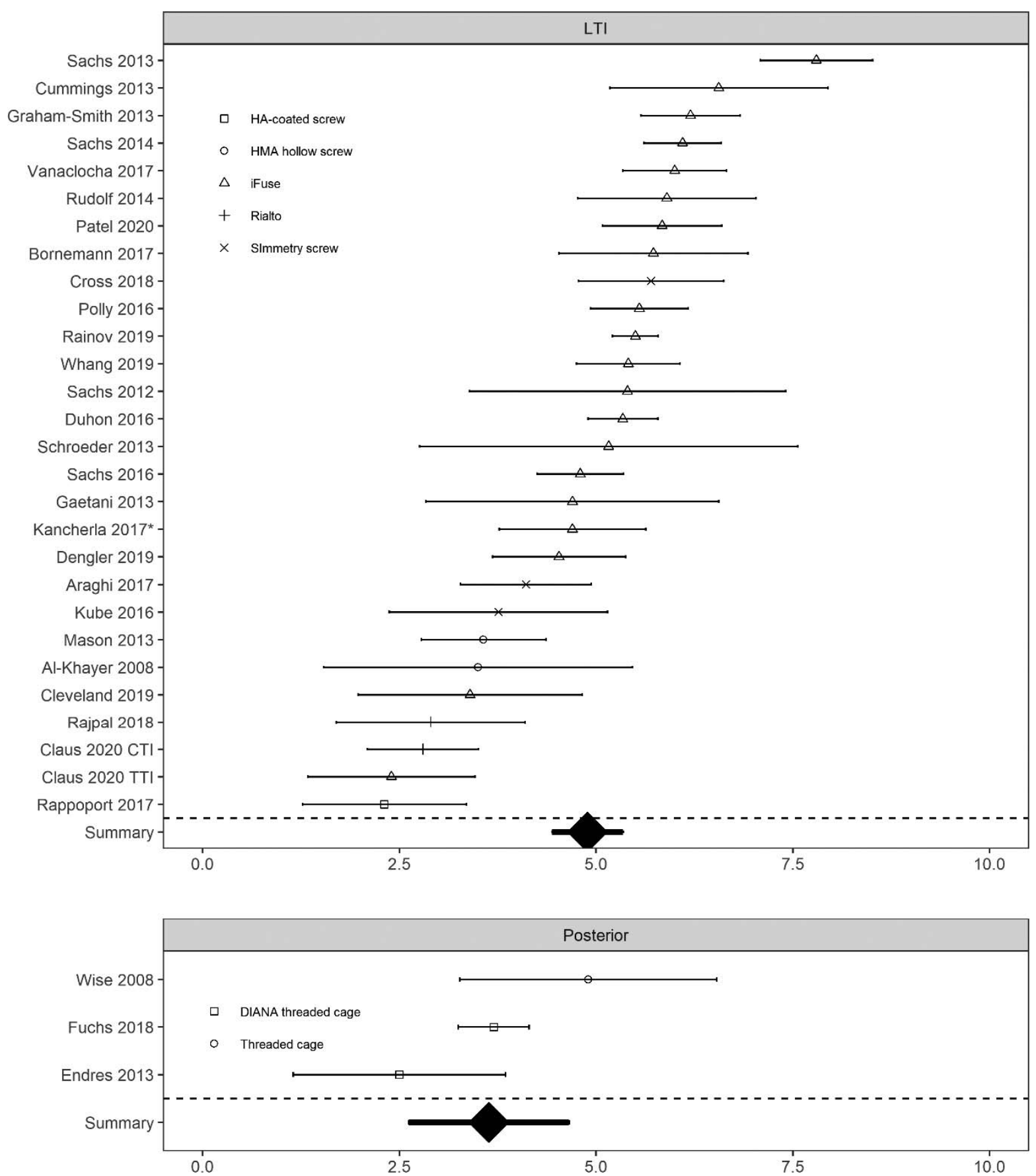

Figure 2. Change in visual analog scale or numeric rating scale sacroiliac joint pain score by study for devices placed by lateral transiliac (LTI) approach or posterior approach. Larger positive values mean more improvement. Device type shown by shape. Horizontal bracketed bars denote confidence limit. Note that Wise 2008 reported change scores but not population means at baseline and follow-up.

strated bridging bone across the articular SIJ adjacent or distant to the implants in $85 \%$ of patients.

Study of Bone Growth in the Sacroiliac joint after Minimally Invasive Surgery with Titanium Implants (SALLY). In SALLY, a prospective multicenter clinical trial of a 3D-printed version of iFuse TTI
(iFuse-3D), nearly identical improvements in pain, disability, and QOL were observed in 51 patients at 1 year after SIJF. ${ }^{160}$ ODI improved from 52.8 at baseline to 27.9 and SIJ pain improved from 78 preoperatively to 21 at 12 months $(0-100$ scale, $P=$ $.0001)$. There were 2 revision surgeries $(3.9 \%)$ : 1 revision to reposition a symptomatic malpositioned implant, and 1 revision after a motor vehicle 
accident. CT scans at 6 months and 1 year showed a high and increasing rate of bridging bone.

Evolusion. In Evolusion, a prospective, multicenter trial evaluating placement of the SImmetry implant (RTI Surgical), similar results were seen in the first 50 patients at 6 months' follow-up. ${ }^{161}$ Clinical results of 50 patients at 24 months showed improvement in VAS back pain (75.2 to 30.1) and improvement in ODI (55.2 to 26.9). One revision surgery to treat a symptomatic malposition was reported.

SI-LOK Study. Rappoport et $\mathrm{al}^{162}$ reported a prospective, multicenter trial of use of SI-LOK (Globus, Inc), a hydroxyapatite-coated screw, for SIJF in 32 subjects. ${ }^{162}$ VAS low back pain decreased from 55.8 at baseline to 28.5 at 12 months; ODI improved from 55.6 to 34.6. Two revision surgeries were reported in the first 12 months. Two-year results of 50 patients were recently presented. Improvements were noted in VAS back pain (30.1 points) and VAS leg pain (27.0 points) at 24 months.'

A pooled analysis of patient-level data from the 3 prospective trials of TTI ( 2 level I and 1 level II studies) was published in Spine. ${ }^{163}$ This analysis showed similar improvements in pain, function, and QOL across studies and geographies (United States and Europe). Among patients undergoing SIJF, smokers had slightly lower but still clinically important improvements in pain, disability, and QOL scores. Similarly, patients taking opioids at baseline had somewhat lower (but still clinically important) improvements. Of the 326 patients undergoing SIJF with these lateral transfixing devices, $1.2 \%(\mathrm{n}=4)$ had an early $(<1$ month $)$ surgical revision and $2.8 \%(\mathrm{n}=9)$ had a late $(>1$

\footnotetext{
"Kuchazyk DW. Clinical and radiographic outcomes following minimally invasive sacroiliac joint fusion with decortication. ISASS 2020 presentation. February 27, 2020; San Juan, Puerto Rico. https://www.eventscribe.com/2015/ app/presentationslides/slideshare.asp?sfp=OTU0OHwx MTcyODY0fDM5NDk4NDk1fC0x. Accessed October 20, 2020.

Rappoport LH. Minimally invasive sacroiliac joint fusion using a novel hydroxyapatite-coated screw: two-year clinical and radiographic outcomes. ISASS 2020 presentation. February 27, 2020; San Juan, Puerto Rico. https://www. eventscribe.com/2015/app/presentationslides/slideshare. asp?sfp=OTU0OHwxMTcyODY0fDM5NDk4NDk1fC0. Accessed October 20, 2020.
}

month) surgical revision. Large observed effect sizes suggest a true underlying treatment effect. The authors found no predictors of outcomes in the nonsurgical groups.

\section{Level III Studies}

Several comparative retrospective case series of lateral transiliac MIS SIJF have been published. In these studies, operative measures (duration of surgery, blood loss, length of stay) were lower in MIS SIJF with TTI compared to open anterior $^{119,120}$ or open posterior SIJF procedures. ${ }^{117}$ Implant survivorship (ie, freedom from surgical revision) at 4 years was superior in patients undergoing SIJF with TTI versus those treated with iliosacral fixation screws. ${ }^{164}$ Vanaclocha et al $^{165}$ reported superior outcomes of patients treated with TTI compared to both conservative care and RF ablation of the sacral nerve root branches out to 6 years. Finally, Claus et al ${ }^{166}$ reported a single-center experience using either cylindrical threaded implants (CTI) (Rialto, Medtronic, Inc), or TTI. Surgical time was slightly less with TTI compared to CTI. There was no significant difference in patientreported outcomes for VAS back, VAS leg, ODI, or SF-12 at 6 or 12 months between the 2 cohorts. The revision rate for CTI was higher than for TTI $(6.1 \%$ versus $2.4 \%, P=.11)$.

\section{Level IV Studies}

Several case series add to the literature supporting lateral transiliac MIS SIJF with placement of transfixing device(s). ${ }^{167-185}$ These studies demonstrate generally consistent results across device types within this group and among geographies. Longterm studies with 5- ${ }^{178}$ and 6-year ${ }^{165}$ follow-up were similar to results of a prospective 5-year study of iFuse. ${ }^{159}$

\section{Reviews}

Several reviews (narrative, systematic, and metaanalysis) have been published focusing on lateral transiliac MIS SIJF with transfixing devices. ${ }^{186-193}$ These reviews support the previously stated conclusions, including that lateral MIS SIJF is beneficial (proven improvements in pain and function) in appropriately selected patients with SIJ pain.

\section{Safety Studies}

Complications. The prospective clinical trials of lateral transiliac MIS SIJF consistently demonstrate 
the safety and effectiveness of the approach. Adverse events in the clinical trials and in other studies have been consistently low (see Appendix Table A2). Schoell et al $^{194}$ published an analysis of the Humana insurance claims database evaluating MIS SIJF for the time period 2007-2014. They reported an overall complication rate of $13.2 \%$ at 90 days and a $16.4 \%$ at 6 months. Most complications were wound and urinary tract infections $(4.1 \%)$. As described in the paper, the authors did not have access to individual patient records; it is likely that this type of analysis captured patients who did not have lateral transiliac MIS SIJF procedures and/or patients who had a complication that was unrelated to the SIJF procedure. Thus, these numbers are likely overstated.

Revisions. Surgical revision rates in prospective studies of TTI and other devices are relatively low, ranging from $1 \%-5 \% .{ }^{157,158}$ SI-BONE, Inc (manufacturer of iFuse TTI) reported lower complication rates in an analysis of spontaneously reported events. ${ }^{195}$ The complaint rate of $3.8 \%$ likely understates the true rate as all events are likely not captured through the described reporting mechanism. A second study focusing on implant survivorship showed a $96.5 \%$ survivorship at 4 years in over 11000 procedures performed in the United States. ${ }^{196}$ The 4-year cumulative revision rate $(3.5 \%)$ did not vary by age $(<65$ or $>65)$ or sex. A third study by the same manufacturer compared survivorship between first-generation (11 070 cases) and second-generation (3D-printed, 3140 cases) TTI. ${ }^{197}$ There were no significant differences in complaints between the 2 generations of devices with an overall complaint rate of $1.3 \%$. The cumulative 1-year probability of revision was $1.5 \%$ for the first-generation device and $1.0 \%$ for the 3Dprinted device $(P=.0408)$.

\section{Biomechanical Studies}

Two recent reviews provide summary information on SIJ biomechanics and the effects of lateral transfixing devices. ${ }^{198,199}$ Several other studies have evaluated the effectiveness of specific lateral transfixing devices, ${ }^{200-206}$ and have shown that these devices immediately stabilize the SIJ. Studies have shown that fusing the SIJ results in minimal stress transfer to adjacent joints. Lateral MIS SIJF results in minimal increase or decrease in motion or stress at the contralateral $\mathrm{SIJ},{ }^{207}$ minimal increase in motion at the L4-L5 or L5-S1 motion segment, ${ }^{208}$ and limited $(5 \%)$ increase in stress at the hip joint. $^{209}$ The amount of stress transfer to adjacent segments after lateral transiliac SIJF is far less than the stress transfer to the SIJ after a lumbar fusion, namely a $52 \%$ increase in SIJ motion after a L5-S1 fusion and $168 \%$ after fusion from L4 to the sacrum. ${ }^{29}$

\section{Economic Analyses}

Cost-Effectiveness. Multiple authors have evaluated the economic aspects of lateral transiliac MIS SIJF with joint-transfixing devices. In INSITE, the USbased randomized trial of TTI for lateral transiliac MIS SIJF, embedded healthcare utilization collection informed a Markov process cost-utility model, which showed a very modest incremental costeffectiveness ratio of \$13 300/QALY (Quality Adjusted Life Year) compared to nonsurgical treatment. ${ }^{210}$ SIJF with TTI was determined to be cost-effective in the short term and likely costsaving in the longer term. The incremental costeffectiveness ratio for lateral MIS SIJF with TTI (\$13 300/QALY) is similar to that of hip (\$10 000/ QALY) and knee (\$13 000/QALY) arthroplasty. Ackerman et al have shown the high cost and medical utilization in both the US Medicare ${ }^{211}$ and commercial payor populations. ${ }^{212}$ Publications by the same authors showed cost savings over time in both the Medicare ${ }^{213}$ and commercial payer ${ }^{214}$ populations when a patient is treated with lateral MIS SIJF versus continued nonsurgical management.

Physician Work and Resource Utilization. A retrospective comparative study utilizing Navicare data showed that operative time for lateral MIS SIJF Current Procedural Terminology (CPT) code 27279 was not statistically different from open microdiscectomy CPT 63030 (112 minutes versus 119 minutes $(P=.135)) .{ }^{154}$ Postoperative work was found to be greater for MIS SIJF than for open microdiscectomy. A work-intensity study comparing CPT 27279 to CPT 63030 showed preoperative, intraoperative, and postoperative workload for MIS SIJF with lateral transfixing device was higher than for open microdiscectomy CPT 63030. ${ }^{153}$ In 2015, the International Society for the Advancement of Spine Surgery (ISASS) conducted a study consisting of a Rasch analysis of 2 separate surveys of surgeons to assess work and assigned relative value units (RVU) for CPT 27279 MIS SIJF with a lateral 
transfixing device. ${ }^{155}$ The regression analysis of the results of the 2 studies indicates a work RVU for CPT 27279 of 14.23 .

\section{POSTERIOR (DORSAL) MIS PROCEDURES}

\section{Procedure Description}

The posterior (dorsal) MIS SIJF procedure is a recognized and well-described distinct surgical procedure. ${ }^{192,193,215}$ In the dorsal approach, allograft bone products or devices are placed into the ligamentous portion of the joint via dissection of the multifidus muscle and removal of a portion of the ligaments covering the dorsal, posterior aspect of the joint. A portion of the interosseous SIJ ligament is also typically removed. ${ }^{192,193,215}$

The posterior (dorsal) MIS SIJF procedure is distinct from lateral transiliac MIS SIJF using transfixing devices (CPT code 27279) in several fundamental ways:

(1) The surgical anatomy, being distinct, likely carries different risks that, to this point, are not well studied.

(2) The surgeon's work effort is distinct with the dorsal procedure requiring less surgical dissection, and the procedure generally taking much less time.

(3) Initial stabilization is not achieved via transfixion with a laterally placed device, but rather by ligamentotaxis (tensioning of the ligaments supporting the SIJ via placement of a bone graft or device into the ligamentous SIJ).

(4) Long-term stabilization or fusion is achieved via distraction arthrodesis rather than by integration of the surrounding bone of the ilium and sacrum into or onto the transfixing implants with eventual bridging bone across the SIJ adjacent to the implants. Distraction arthrodesis of the SIJ consists of placement of an implant or bone allograft into the ligamentous portion of the SIJ, thus "distracting the joint." This places the supporting ligaments under tension, theoretically stabilizing the joint. Bone graft and/ or recombinant human bone morphogenetic protein (rhBMP) are then utilized to achieve bone fusion. Distraction arthrodesis has also been described in the lumbar spine using stand-alone bone allograft ${ }^{216}$ and stand- alone fusion cages in the early 2000 s. $^{217,218}$ The results and clinical experience of ligamentotaxis and distraction arthrodesis are well described in the lumbar spine literature. These treatment strategies have fallen out of favor secondary to problems with both allografts (pseudarthrosis secondary to graft fracture or resorption) and cages (migration and subsidence, loss of lumbar lordosis, high pseudarthrosis rates, and the established need for supplemental spinal fixation ${ }^{219}$ ). Currently, only 3 low-quality studies address the safety and effectiveness of MIS posterior SIJF with distraction arthrodesis. ${ }^{220-222}$ There is no safety or effectiveness literature supporting the use of the latest generation of bone allograft products for posterior MIS SIJF.

(5) The majority of the products (bone allograft) used in the dorsal MIS SIJF procedure are not medical devices cleared through the FDA Center for Devices and Radiological Health Premarket Notification process enumerated in section $510(\mathrm{k})$ of the federal Food, Drug, and Cosmetic Act. Rather, these allograft bone products are typically regulated through the FDA Center for Biologics Evaluation and Research, responsible for regulating human cell and tissue products. Certain human cell and tissue products are regulated under section 361 of the Food, Drug, and Cosmetic Act. These products must meet the criteria for "minimally manipulated tissue" outlined in 21 CFR 1271.109(a) and are not required to be licensed, cleared or approved by the FDA. No equivalence testing is required, and these are unclassified products per FDA regulations. Their labeling must reflect the manufacturer's intent that they be used only for homologous use (nonspecific to any product claim).

(6) The level of support in the clinical literature for the posterior (dorsal) MIS SIJF procedure is far lower than for the lateral MIS SIJF procedure.

Due to these differences, data from studies of lateral MIS transiliac SIJF with transfixing devices are likely not generalizable to these posterior (dorsal) MIS SIJF procedures. 


\section{Clinical Evidence}

There is limited published clinical evidence supporting the safety and effectiveness of posterior (dorsal) MIS SIJF. There is 1 prospective multicenter study, ${ }^{222}$ no comparative studies, and only a small number of case series. ${ }^{12,221}$ All published studies describe placement of bone grafts or devices within the ligamentous SIJ.

\section{Fibular Allograft}

McGuire et $\mathrm{al}^{112}$ published the results of a retrospective series of 37 patients where fibular strut allografts were placed dorsally into the SIJ. Results presented in this paper are likely not generalizable to the current posterior MIS SIJF procedure performed with allograft products. This is primarily due to the procedure being studied. While labeled as MIS by the authors, the procedure included a large incision over the posterior iliac crest with subperiosteal exposure of the medial and lateral aspects of the posterior crest. Authors then performed an osteotomy of the posterior iliac crest to gain access to the articular SIJ after debridement of the interosseous ligament. These steps are not typical of the procedural steps described for current posterior (dorsal) MIS SIJF with contemporary allograft products or devices. These steps would be more typical of an open posterior SIJF procedure. ${ }^{14,115,117}$ Autograft from the osteotomized iliac crest was placed into the articular joint and the fibular struts were placed from the dorsal aspect of the joint across the debrided ligamentous portion of the joint to the ventral articular portion of the SIJ. It is not possible to access the articular SIJ from this trajectory without an osteotomy of the overlying iliac crest. The fibular struts were greater than 10-12 $\mathrm{mm}$ in diameter and were several centimeters in length. Autogenous bone grafting of the dorsal sacrum and adjacent ilium bones was also part of this procedure. The results of the procedure showed, at 52 months (range 24-62), improvement in VAS of 4 points, and a fusion rate of $89 \%$. There were 4 $(11 \%)$ nonunions treated with open revision fusion.

The current posterior MIS SIJF procedure and products differ greatly from that described by McGuire et al. ${ }^{112}$ The current graft products used in the dorsal procedure are much smaller than the fibular grafts. They are placed into a different portion of the joint (primarily into the ligamentous portion of the joint). These procedures are not considered to be "open" procedures, and are performed with no osteotomy of the iliac crest and no debridement of the dorsal or interosseous ligaments. They are typically performed without autogenous bone grafting of the articular joint, the dorsum of the sacrum, and the medial ilium. These newer allograft products are placed through a small incision(s) in a true MIS or even percutaneous manner. The physician work, length of surgical procedure, and resource utilization are much less with the newer products and the MIS dorsal procedure.

\section{Fusion Cages}

One FDA-cleared medical device for posterior MIS SIJF (NADIA, Ilion Medical, Inc) employs similar stabilization (ligamentotaxis) and fusion (distraction arthrodesis) strategies. NADIA is an iteration of the DIANA fusion cage** (Signus, available only in Europe). No published studies document the safety and effectiveness of NADIA. A small retrospective case series reported 13-month results in 19 patients treated with the DIANA cage. ${ }^{221}$ Improvement from baseline to final follow-up in pain scores ( 8.5 to 6 ) and disability (ODI, 64 to 57 ) appears to be less than that observed with other approaches or devices. Estimated blood loss was less than $150 \mathrm{~mL}$ in all cases and length of stay was 7.3 days. Bone fusion described as bridging bone across the SIJ and absence of loosening around the implant was present in $79 \%$ of patients. A prospective, multicenter cohort using the same device in 171 patients showed somewhat larger 2-year improvements in SIJ pain (74 to 37) and ODI (51 to 33). ${ }^{222}$ Bone fusion described as bridging bone across the SIJ as evaluated on CT scan at 2 years was present in $31 \%$ of patients. This is less than bridging bone fusion of lateral transiliac MIS approaches with lateral transfixing devices shown in prospective trials of TTI ( $51 \%$ at 2 years and $85 \%$ at 5 years). ${ }^{159}$

Other reports of posterior MIS SIJF with distraction arthrodesis using cylindrical threaded cages filled with bone morphogenetic protein have cited higher fusion rates. Wise and Dall ${ }^{220}$ reported a prospective series of 13 patients treated with threaded fusion cages and rhBMP (notably, neither device is FDA-cleared for SIJF). VAS low back pain improved 4.9 points and VAS leg pain improved 2.8 points. There was 1 revision surgery for symptom-

\footnotetext{
**https://signus.com/intl/products/portfolio/dianasacroliliac-fusion.html. Accessed October 20, 2020.
} 
atic pseudarthrosis. The fusion rate assessed on CT at 6 months was $79 \%$. Other reported series also reported a higher fusion rate with use of rhBMP. Stark et $\mathrm{al}^{223}$ presented a series of SIJF cases using the DIANA cage with rhBMP reporting a fusion rate of $92 \%$. Freeman reported a fusion rate of $89 \%$ at 24 months in a series of 38 patients undergoing SIJF using DIANA cages and rhBMP, many performed in conjunction with concurrent instrumented lumbar fusion. ${ }^{\dagger \dagger}$

One additional device (Catamaran SIJ Fixation System, Tenon Medical, Inc) is FDA-cleared for MIS SIJF using a posterior approach. Rather than relying on ligamentotaxis and distraction arthrodesis, this device is placed across the posterior aspect of the inferior limb of the articular SIJ with one "outrigger" placed into the ilium and one into the sacrum. A scaffold connects the 2 outriggers. Biomechanical studies suggest that SIJ stabilization relies on lateral transfixion and avoiding disruption of the posterior interosseus and dorsal SIJ ligaments. ${ }^{203}$ Several other biomechanical studies have shown the effectiveness of various lateral transfixing devices for stabilizing the SIJ. ${ }^{200-202,204-207}$ As the Catamaran device is placed perpendicular to the axis of rotation (as opposed to placement parallel to the axis of rotation), the device does not engage the dense bone of the lateral iliac cortex. No biomechanical or clinical studies, to date, provide supportive evidence for this device.

\section{LITERATURE SEARCH}

A literature search was performed using the terms "sacroiliac joint" and "fusion or arthrodesis" and the PubMed interface to Medline; 439 hits were identified and abstracts reviewed. Relevant articles describing clinical results reported in prospective trials, retrospective case series, case reports and review articles are presented in Appendix, Table A2. See Appendix, Figure A1, Literature Search Exclusions Flow Chart, for the literature search strategy. Further numeric analysis was performed as follows.

\footnotetext{
${ }^{\dagger \dagger}$ Freeman T. 107- Improvement in Sacroiliac Joint Pain 2 Years after Fusion with the Distraction Interference Arthrodesis (DIANA ${ }^{\mathrm{TM}}$ ) Device. Poster presented at the: ISASS 16th Annual Meeting-Oral Podium and Oral Poster Presentations; April 6; Las Vegas, Nevada. Accessed October 1, 2020. https://www.isass.org/ abstracts/isass 16-oral-posters/isass 16-107-Improvement-inSacroiliac-Joint-Pain-2-Years-after-Fusion-with-the-Dis. html
}

For each article reporting either a case series or prospective study, data were abstracted for $n$, mean and SD of SIJ pain scores and ODI at both baseline and final follow-up. Change scores (from baseline to last follow-up) were also collected. Where sample sizes at final follow-up were low due to incomplete follow-up, an earlier time point was selected. Some articles did not report some SD values. Missing SD values were imputed conservatively using values derived from graphical analysis of SD as a function of study sample size. Data were entered into Excel and analyzed using $\mathrm{R}$ and the metafor package. Each plot shows the mean observed value and 95\% confidence limits per study at baseline and last follow-up (VAS pain: Figure 1 and Figure 2) or the mean change from baseline and last follow-up and 95\% confidence limits (ODI: Figure 3 and Figure 4). Summary values with $95 \%$ confidence limits derived from random effects meta-analysis are shown at the bottom of each panel. Random effects metaregression was performed comparing score improvements across surgical approaches (lateral transiliac versus posterior).

\section{Numeric Synthesis}

Meta-analysis was performed; graphical results are provided below.

SIJ pain scores were consistently and substantially lower at follow-up compared to baseline across studies and surgical approaches. Meta-analytic summaries showed similar baseline pain scores across procedure types but slightly lower scores at follow-up in studies using devices placed by a lateral transiliac approach (Figure 1). Score improvements were slightly larger for lateral transiliac studies (by 1.2 points [0-10 scale], $P=.1497$, Figure 3 ). There were some differences in outcomes between the lateral transfixing devices. Rialto and hydroxyapatite-coated screws appeared to show smaller changes.

For ODI scores, a similar pattern was observed with substantially lower scores at follow-up compared to baseline across studies. Final follow-up ODI scores appeared lower (better) for the lateral transiliac procedure; see Figure 2. ODI improvement from baseline was slightly larger (by 12 points, $P=.1722$ ) in studies using the lateral transiliac

\footnotetext{
*Viechtbauer W. Conducting meta-analyses in $\mathrm{R}$ with the metafor package. J Stat Softw. 2010;36(3):1-48. https:// www.jstatsoft.org/v036/i03.
} 

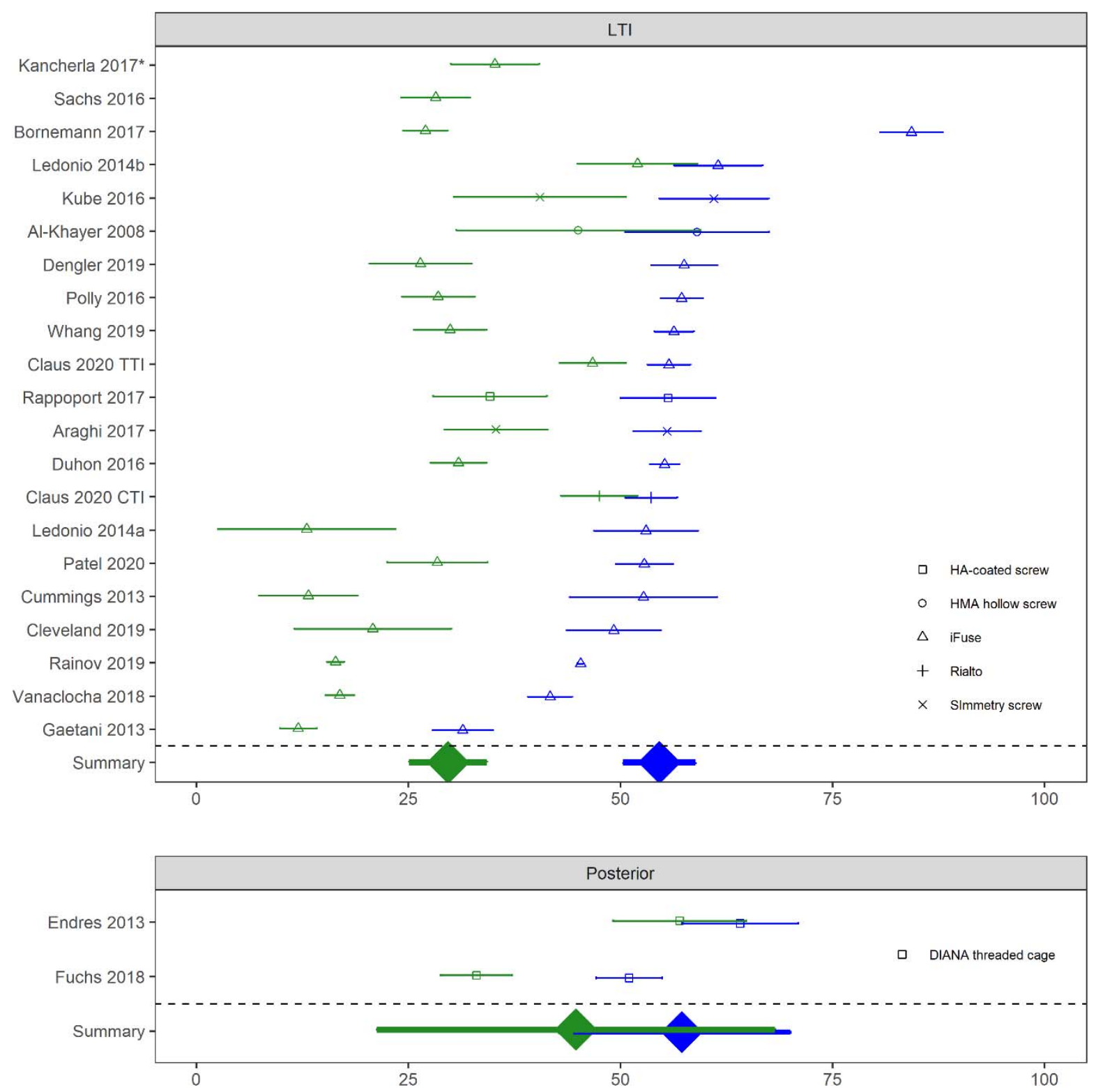

Figure 3. Baseline (blue) and last follow-up (green) ODI scores in cohorts of patients treated with lateral transiliac (LTI) sacroiliac joint fusion (SIJF) or posterior SIJF. Two studies did not report baseline ODI scores. Device type shown by shape. Horizontal bars denote confidence limit.

approach compared to the posterior approach. Analysis was limited by the small number of studies reporting score improvements after the posterior procedure. For the lateral transfixing devices, the only published Rialto study showed smaller ODI improvements (but changes in the TTI group in the same study were also relatively small).

\section{INDICATIONS AND LIMITATIONS OF COVERAGE}

Patients who have all of the following criteria may be eligible for lateral transiliac MIS SIJF with placement of lateral transfixing devices:
- Chronic SIJ pain (pain lasting at least 6 months).

- Significant SIJ pain that impacts QOL or significantly limits activities of daily living.

- SIJ pain confirmed with at least 3 physical examination maneuvers that stress the SIJ (see list provided above) and reproduce the patient's typical pain.

- Confirmation of the SIJ as a pain generator with $\geq 50 \%$ acute decrease in pain upon fluoroscopically guided diagnostic intra-articular SIJ block using a small volume $(\leq 2.5 \mathrm{~mL})$ of local anesthetic. Prospective trials have shown that patients with SIJ pain responses of 

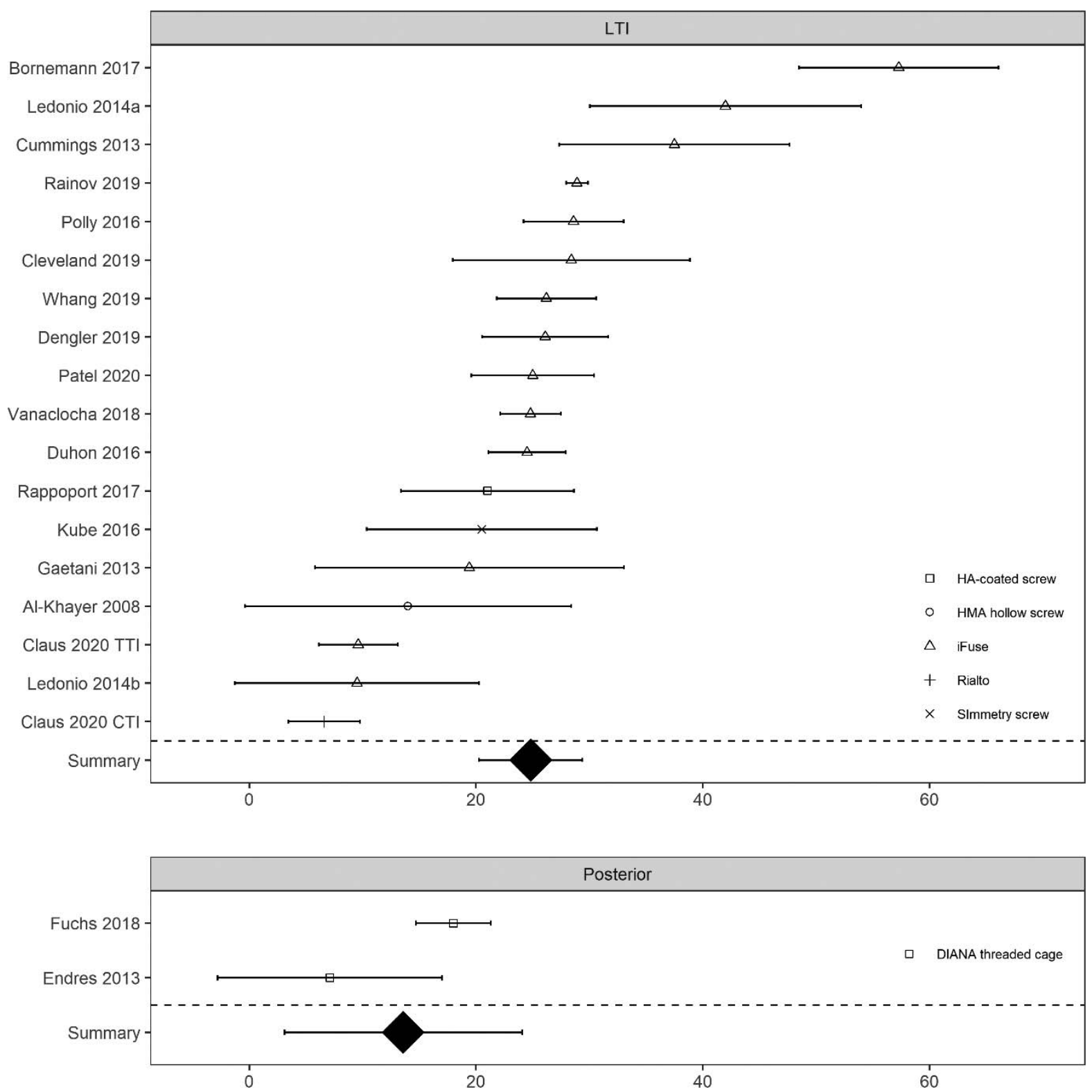

Figure 4. Change in Oswestry Disability Index by study for devices placed by lateral transiliac (LTI) procedure and posterior procedure. Larger positive values mean more improvement. Device type shown by shape. Horizontal bracketed bars denote confidence limit.

$50 \%-75 \%$ respond to MIS SIJF as well as those with $75 \%-100 \%$ acute responses. ${ }^{72}$

- Failure to respond to nonsurgical treatment consisting of NSAIDs and a reasonable course (4-6 weeks) of PT. Failure to respond means continued pain that interferes with activities of daily living and/or results in functional disability.

- Intra-articular SIJ steroid injection may be considered but is not required as there is no high-quality evidence supporting the safety and effectiveness of this intervention and there are potential risks and significant costs asso- ciated with this intervention. Treatment with repeat intra-articular steroid injection is not recommended.

- RF ablation of SIJ lateral branch nerves may be considered but is not required as there is only modest evidence supporting the safety and effectiveness of the procedure. There are currently no standardized patient selection algorithms, no standardized technology, and no standardized techniques. There are significant costs associated with the procedure. Treatment with repeat SIJ RF ablation is not recommended. 
- Additional or alternative diagnoses that could be responsible for the patient's ongoing pain or disability have been considered. Physicians should consider that patients can have multiple pain generators and addressing just one pain generator may not relieve all disability or all back pain.

MIS SIJF is not indicated for patients with the following:

- Less than 6 months of SIJ pain and/or functional impairment.

- Failure to pursue conservative treatment of the SIJ (unless contraindicated).

- Pain not confirmed with a diagnostic SIJ block.

- Presence of other pathology that would substantially prevent the patient from deriving benefit from SIJF.

MIS posterior (dorsal) SIJF is not recommended.

Bilateral SIJ pain is not uncommon. Diagnosis of bilateral SIJ pain must be made on the basis of a history of bilateral pain, bilateral elicitation of pain on physical examination maneuvers that stress each SIJ, and acute bilateral decrease in pain upon fluoroscopically guided intra-articular SIJ block with local anesthetic. Bilateral SIJF is probably best performed serially as successful treatment of one side may improve pain/disability to a degree acceptable to the patient. SIJF of the contralateral side may be necessary if contralateral SIJ pain continues and disability is significant for the patient. If bilateral fusion is performed at the same operative session, the surgeon must document both medical necessity and why serial fusion is not indicated in the patient.

It is expected that a person would not undergo more than 1 SIJF per side per lifetime except in the rare case that a revision is needed.

\section{CODING}

\section{Open SIJF}

The American Medical Association (AMA) recommends open SIJF be coded using CPT code 27280. Open SIJF may be performed from an anterior, posterior, or lateral transiliac (SmithPetersen) approach, and all are appropriately reported via CPT 27280. The February 2014 AMA CPT Panel meeting revised CPT 27280 to include the word "open" and in addition to the anterior subiliacus approach found within the vignette, clarified further an anterior retroperitoneal approach. A second vignette describing a lateral transiliac (Smith-Petersen) approach was added. The open procedure, regardless of approach (anterior, lateral, posterior) includes extensive surgical dissection and access to the SIJ that allows visualization and excision of the dorsal and intraosseous ligaments in the posterior approach, excision of the intraosseous ligament in the lateral approach, and excision of the anterior joint capsule in an anterior approach with osteoclasis and grafting of the articular SIJ as a procedural component in all 3 approaches. Use of stabilizing fixation is typically performed in all 3 approaches. Fixation (regardless of type) is included as part of 27280. The American Medical Association (AMA) relative value scale (RVS) Update Committee (RUC) assigned intraservice time for the open procedure of 120 minutes; additionally, 2 postoperative in-hospital evaluation and management visits are associated with this code.

\section{Lateral Transiliac MIS SIJF}

The AMA recommends minimally invasive lateral transiliac SIJF with transfixing devices be coded using CPT code 27279. CPT 27279 includes bone grafting when performed and placement of transfixing devices. For bilateral procedures, report 27279 with modifier -50 .

\section{Posterior (Dorsal) MIS SIJF}

Minimally invasive posterior (dorsal) SIJF should be coded using 22899 (unlisted procedure, spine) or 27299 (unlisted procedure, pelvis or hip joint). ${ }^{224}$ This includes placement of any device or product type which does not involve placement of a lateral transiliac transfixing device extending through the ilium, across the SIJ, and into the sacrum.

\section{Hybrid: Lateral MIS with Dorsal Placement of Bone Graft}

Procedures utilizing an MIS trajectory for placement of lateral transiliac transfixing devices, as well as for posterior placement of bone graft or other devices or products secondary to the primary (lateral MIS) procedure, should consider the primary CPT code for lateral MIS SIJF procedures (CPT 27279). Add-on CPT coding may be appropriate to report the addition of structural or osteopromotive 
bone allograft material placed posterior (dorsal) into the SIJ (eg, +20930, +20931).

Surgeons performing an open approach to the SIJ with associated surgical dissection to perform excision of the dorsal and interosseous ligament tissue and osteoclasis and grafting of the articular joint should consider CPT 27280 as well as any addon CPT coding that may be appropriate to report services or procedures performed.

\section{SIJF in Conjunction with Multi-Segment Spinal Fusion (Including Pelvic Fixation)}

Pelvic fixation (eg, rods and connectors in a Galveston technique configuration) is commonly reported with add-on CPT code 22848. This may include placement of bolts and screws to fixate the pelvis. This may also be performed in conjunction with open or MIS SIJF, reported via CPT codes 27280 or 27279 , respectively. TTIs (iFuse Implant System, SI-BONE, Inc) and some other devices are FDA-cleared to augment immobilization and stabilization of the SIJ as part of a lumbar or thoracolumbar fusion involving pelvic fixation.

\section{Revision/Removal Procedures}

Revision and/or removal of the SIJ implant would typically be coded using 22899 (unlisted procedure, spine) or 27299 (unlisted procedure, pelvis or hip joint) depending on the type of approach and procedure performed, whether within the global period of the fusion, or not.

\section{DOCUMENTATION REQUIREMENTS}

- A complete history and physical documenting the likely existence of SIJ pain

- Performance of a fluoroscopically-guided intra-articular SIJ block on the affected side (or both sides, see discussion above) which shows at least a $50 \%$ acute reduction in pain

- A course of conservative treatment to include use of NSAIDs and one of the following: (1) an adequate period of rest and activity modification, (2) an adequate course of physical therapy wherein the physical therapist specifically documents lack of response to treatment

- SIJ pain has continued for a minimum of 6 months
- Other diagnoses that could be causing the patient's pain have been considered and the physician believes that SIJF is clinically required

\section{SURGEON QUALIFICATIONS}

- MIS SIJF is a surgical procedure performed by orthopedic or neurologic surgeons who have successfully completed a residency in that specialty as well as at least 1 specialized training course in the procedure. Training should include device placement in cadavers or other anatomic training models under supervision of a surgeon experienced in the procedure.

- Surgeons performing MIS SIJF should be specifically credentialed and/or privileged by at least 1 hospital to perform the procedure.

\section{COVERAGE/CONCLUSION}

Lateral MIS transiliac procedures for SIJF have become a recognized safe, predictable, and preferred surgical method for the management of intractable, debilitating primary or secondary SIJ pain disorders. $^{215}$ The lateral procedure should be coded with CPT code 27279. The posterior (dorsal) MIS SIJF procedure is significantly distinct from the lateral procedure and is, as of yet, unproven. The posterior MIS procedure, regardless of device or product, should be coded with an unlisted procedure code.

The ISASS policy does not endorse any specific MIS SIJ system. There are numerous devices available that have received FDA $510(\mathrm{k})$ clearance for use in MIS or percutaneous lateral SIJF stabilization. The instrumentation utilized in a MIS SIJ procedure is the purview of surgeon preference.

\section{REFERENCES}

1. Vleeming A, Schuenke MD, Masi AT, Carreiro JE, Danneels L, Willard FH. The sacroiliac joint: an overview of its anatomy, function and potential clinical implications. $J$ Anat 2012;221(6):537-567. doi:10.1111/j.1469-7580.2012.01564.x

2. Cohen SP. Sacroiliac joint pain: a comprehensive review of anatomy, diagnosis, and treatment. Anesth Analg. 2005;101(5):1440-1453. doi:10.1213/01.ANE.0000180831. 60169.EA

3. Dietrichs E. Anatomy of the pelvic joints - a review. Scand J Rheumatol Suppl. 1991;88:4-6.

4. Szadek KM, Hoogland PV, Zuurmond WW, de Lange JJ, Perez RS. Nociceptive nerve fibers in the sacroiliac joint in 
humans. Reg Anesth Pain Med. 2008;33(1):36-43. doi:10.1016/j. rapm.2007.07.011

5. Sturesson B, Selvik G, Udén A. Movements of the sacroiliac joints. A roentgen stereophotogrammetric analysis. Spine. 1989;14(2):162-165.

6. Vleeming A, Albert HB, Östgaard HC, Sturesson B, Stuge B. European guidelines for the diagnosis and treatment of pelvic girdle pain. Eur Spine J. 2008;17(6):794-819. doi:10.1007/ s00586-008-0602-4

7. Ikeda R. Innervation of the sacroiliac joint. Macroscopical and histological studies [in Japanese]. Nihon Ika Daigaku Zasshi. 1991;58(5):587-596.

8. Szadek KM, Hoogland PVJM, Zuurmond WWA, De Lange JJ, Perez RSGM. Possible nociceptive structures in the sacroiliac joint cartilage: an immunohistochemical study. Clin Anat N Y N. 2010;23(2):192-198. doi:10.1002/ca.20908

9. Forst SL, Wheeler MT, Fortin JD, Vilensky JA. The sacroiliac joint: anatomy, physiology and clinical significance. Pain Physician. 2006;9(1):61-67.

10. Murata Y, Takahashi K, Yamagata M, Takahashi Y, Shimada Y, Moriya H. Sensory innervation of the sacroiliac joint in rats. Spine. 2000;25(16):2015-2019.

11. Nakagawa T. Study on the distribution of nerve filaments over the iliosacral joint and its adjacent region in the Japanese [in Japanese]. Nihon Seikeigeka Gakkai Zasshi. 1966;40(4):419-430.

12. Solonen KA. The sacroiliac joint in the light of anatomical, roentgenological and clinical studies. Acta Orthop Scand Suppl. 1957;27:1-127.

13. Grob KR, Neuhuber WL, Kissling RO. Innervation of the sacroiliac joint of the human [in German]. Z Für Rheumatol. 1995;54(2):117-122.

14. Vilensky JA, O'Connor BL, Fortin JD, et al. Histologic analysis of neural elements in the human sacroiliac joint. Spine. 2002;27(11):1202-1207.

15. Roberts SL, Burnham RS, Ravichandiran K, Agur AM, Loh EY. Cadaveric study of sacroiliac joint innervation: implications for diagnostic blocks and radiofrequency ablation. Reg Anesth Pain Med. 2014;39(6):456-464. doi:10.1097/AAP. 0000000000000156

16. Fortin JD, Washington WJ, Falco FJ. Three pathways between the sacroiliac joint and neural structures. AJNR Am J Neuroradiol. 1999;20(8):1429-1434.

17. McGrath MC, Zhang M. Lateral branches of dorsal sacral nerve plexus and the long posterior sacroiliac ligament. Surg Radiol Anat. 2005;27(4):327-330. doi:10.1007/s00276-0050331-X

18. Yang AJ, McCormick ZL, Zheng PZ, Schneider BJ. Radiofrequency ablation for posterior sacroiliac joint complex pain: a narrative review. $P M R$. 2019; Suppl 1:S105-S113. doi: $10.1002 /$ pmrj.12200

19. Cohen SP, Chen Y, Neufeld NJ. Sacroiliac joint pain: a comprehensive review of epidemiology, diagnosis and treatment. Expert Rev Neurother. 2013;13(1):99-116. doi:10.1586/ ern. 12.148

20. Bernard TN, Kirkaldy-Willis WH. Recognizing specific characteristics of nonspecific low back pain. Clin Orthop. 1987; 217(Apr):266-280. doi:10.1097/00003086-198704000-00029

21. Schwarzer AC, Aprill CN, Bogduk N. The sacroiliac joint in chronic low back pain. Spine. 1995;20(1):31-37. doi:10. 1097/00007632-199501000-00007

22. Maigne JY, Aivaliklis A, Pfefer F. Results of sacroiliac joint double block and value of sacroiliac pain provocation tests in 54 patients with low back pain. Spine. 1996;21(16):18891892. doi:10.1097/00007632-199608150-00012

23. Irwin RW, Watson T, Minick RP, Ambrosius WT. Age, body mass index, and gender differences in sacroiliac joint pathology. Am J Phys Med Rehabil. 2007;86(1):37-44. doi:10. 1097/PHM.0b013e31802b8554

24. Sembrano JN, Polly DW. How often is low back pain not coming from the back? Spine. 2009;34(1):E27-32. doi:10. 1097/BRS.0b013e31818b8882

25. Katz V, Schofferman J, Reynolds J. The sacroiliac joint: a potential cause of pain after lumbar fusion to the sacrum. $J$ Spinal Disord Tech. 2003;16(1):96-99.

26. Maigne JY, Planchon CA. Sacroiliac joint pain after lumbar fusion. A study with anesthetic blocks. Eur Spine J. 2005;14(7):654-658. doi:10.1007/s00586-004-0692-6

27. DePalma MJ, Ketchum JM, Saullo TR. Etiology of chronic low back pain in patients having undergone lumbar fusion. Pain Med. 2011;12(5):732-739. doi:10.1111/j.1526-4637. 2011.01098.x

28. Liliang P-C, Lu K, Liang C-L, Tsai Y-D, Wang K-W, Chen H-J. Sacroiliac joint pain after lumbar and lumbosacral fusion: findings using dual sacroiliac joint blocks. Pain Med. 2011;12(4):565-570. doi:10.1111/j.1526-4637.2011.01087.x

29. Ivanov AA, Kiapour A, Ebraheim NA, Goel V. Lumbar fusion leads to increases in angular motion and stress across sacroiliac joint: a finite element study. Spine. 2009;34(5):E162169. doi:10.1097/BRS.0b013e3181978ea3

30. Hashimoto K, Aizawa T, Kanno H, Itoi E. Adjacent segment degeneration after fusion spinal surgery - a systematic review. Int Orthop. 2019;43(4):987-993. doi:10.1007/s00264018-4241-z

31. Hilibrand AS, Robbins M. Adjacent segment degeneration and adjacent segment disease: the consequences of spinal fusion? Spine J Off J North Am Spine Soc. 2004;4(6 Suppl):190S-194S. doi:10.1016/j.spinee.2004.07.007

32. Finger T, Bayerl S, Bertog M, Czabanka M, Woitzik J, Vajkoczy P. Impact of sacropelvic fixation on the development of postoperative sacroiliac joint pain following multilevel stabilization for degenerative spine disease. Clin Neurol Neurosurg. 2016;150:18-22. doi:10.1016/j.clineuro.2016.08.009

33. Elder BD, Ishida W, Lo S-FL, et al. Use of S2-alar-iliac screws associated with less complications than iliac screws in adult lumbosacropelvic fixation. Spine. 2017;42(3):E142-E149. doi:10.1097/BRS.0000000000001722

34. Unoki E, Miyakoshi N, Abe E, Kobayashi T, Abe T, Shimada Y. Sacroiliac joint pain after multiple-segment lumbar fusion: a long-term observational study - non-fused sacrum vs. fused sacrum. Spine Surg Relat Res. 2017;1(2):90-95. doi:10. 22603/ssrr.1.2016-0010

35. Unoki E, Miyakoshi N, Abe E, et al. Sacropelvic fixation With S2 alar iliac screws may prevent sacroiliac joint pain after multisegment spinal fusion. Spine. 2019;44(17):E1024-E1030. doi:10.1097/BRS.0000000000003041

36. Diesing D, Franke J, Tschoeke SK, Schultheiß R, Scheufler KM. Persistent iliosacral joint syndrome following instrumentation to the sacropelvis in patients with adult spinal deformity. J Neurol Surg Part Cent Eur Neurosurg. 2019;80(1):15-25. doi:10.1055/s-0038-1655732

37. Unoki E, Abe E, Murai H, Kobayashi T, Abe T. Fusion of multiple segments can increase the incidence of sacroiliac joint pain after lumbar or lumbosacral fusion. Spine. 2016;41(12):999-1005. doi:10.1097/BRS.0000000000001409

38. Berven S, Wadhwa R. Sagittal alignment of the lumbar 
spine. Neurosurg Clin N Am. 2018;29(3):331-339. doi:10.1016/j. nec.2018.03.009

39. Shin M-H, Ryu K-S, Hur J-W, Kim J-S, Park C-K. Comparative study of lumbopelvic sagittal alignment between patients with and without sacroiliac joint pain after lumbar interbody fusion. Spine. 2013;38(21):E1334-1341. doi:10.1097/ BRS.0b013e3182a0da47

40. Cho D-Y, Shin M-H, Hur J-W, Ryu K-S, Park C-K. Sagittal sacropelvic morphology and balance in patients with sacroiliac joint pain following lumbar fusion surgery. $J$ Korean Neurosurg Soc. 2013;54(3):201-206. doi:10.3340/jkns.2013.54.3. 201

41. Ciarpaglini R, Otten P, Sutter P, Duy VQ, Gautier E, Maestretti G. Sacroiliac joint syndrome 10 years after lumbar arthroplasty: the importance of spinopelvic alignment. Eur Spine J. 2014;23(S6):720-724. doi:10.1007/s00586-014-3547-9

42. Cher D, Polly D, Berven S. Sacroiliac joint pain: burden of disease. Med Devices Evid Res. 2014;7:73-81. doi:10.2147/ MDER.S59437

43. Cher DJ, Reckling WC. Quality of life in preoperative patients with sacroiliac joint dysfunction is at least as depressed as in other lumbar spinal conditions. Med Devices Evid Res. 2015;8:395-403. doi:10.2147/MDER.S92070

44. Riddle DL, Freburger JK. Evaluation of the presence of sacroiliac joint region dysfunction using a combination of tests: a multicenter intertester reliability study. Phys Ther. 2002;82(8):772-781.

45. Dreyfuss P, Michaelsen M, Pauza K, McLarty J, Bogduk $\mathrm{N}$. The value of medical history and physical examination in diagnosing sacroiliac joint pain. Spine. 1996;21(22):2594-2602.

46. Robinson HS, Brox JI, Robinson R, Bjelland E, Solem $\mathrm{S}$, Telje T. The reliability of selected motion- and pain provocation tests for the sacroiliac joint. Man Ther. 2007;12(1):72-79. doi:10.1016/j.math.2005.09.004

47. Freburger JK, Riddle DL. Measurement of sacroiliac joint dysfunction: a multicenter intertester reliability study. Phys Ther. 1999;79(12):1134-1141.

48. Laslett M, Williams M. The reliability of selected pain provocation tests for sacroiliac joint pathology. Spine. 1994;19(11):1243-1249.

49. Laslett M, Aprill CN, McDonald B. Provocation sacroiliac joint tests have validity in the diagnosis of sacroiliac joint pain. Arch Phys Med Rehabil. 2006;87(6):874; author reply 874-875. doi:10.1016/j.apmr.2006.04.007

50. Laslett $M$. The value of the physical examination in diagnosis of painful sacroiliac joint pathologies. Spine. 1998;23(8):962-964.

51. Szadek KM, van der Wurff $P$, van Tulder MW, Zuurmond WW, Perez RSGM. Diagnostic validity of criteria for sacroiliac joint pain: a systematic review. $J$ Pain. 2009;10(4):354-368. doi:10.1016/j.jpain.2008.09.014

52. Schneider BJ, Ehsanian R, Rosati R, Huynh L, Levin J, Kennedy DJ. Validity of physical exam maneuvers in the diagnosis of sacroiliac joint pathology. Pain Med Malden Mass. 2019. doi:10.1093/pm/pnz183

53. Schneider BJ, Rosati R, Zheng P, McCormick ZL. Challenges in diagnosing sacroiliac joint pain: a narrative review. PM R. 2019. doi:10.1002/pmrj.12175

54. Petersen T, Laslett M, Juhl C. Clinical classification in low back pain: best-evidence diagnostic rules based on systematic reviews. BMC Musculoskelet Disord. 2017;18(1):188. doi:10.1186/s12891-017-1549-6

55. Puhakka KB, Jurik AG, Schiøttz-Christensen B, et al.
MRI abnormalities of sacroiliac joints in early spondylarthropathy: a 1-year follow-up study. Scand $J$ Rheumatol. 2004;33(5):332-338. doi:10.1080/03009740410005881

56. McKenzie-Brown AM, Shah RV, Sehgal N, Everett CR. A systematic review of sacroiliac joint interventions. Pain Physician. 2005;8(1):115-125.

57. Cohen AS, McNeill JM, Calkins E, Sharp JT, Schubart A. The "normal" sacroiliac joint. Analysis of 88 sacroiliac roentgenograms. Am J Roentgenol Radium Ther Nucl Med. 1967;100(3):559-563.

58. Elgafy H, Semaan HB, Ebraheim NA, Coombs RJ. Computed tomography findings in patients with sacroiliac pain. Clin Orthop. 2001;(382):112-118.

59. Puhakka KB, Boel LW, Vesterby A, Egund N, Melsen F, Jurik AG. MR imaging of the normal sacroiliac joint with correlation to histology. Skeletal Radiol. 2004;33(1):15-28. doi:10.1007/s00256-003-0691-4

60. Slipman CW, Sterenfeld EB, Chou LH, Herzog R, Vresilovic E. The value of radionuclide imaging in the diagnosis of sacroiliac joint syndrome. Spine. 1996;21(19):2251-2254.

61. Maigne JY, Boulahdour H, Chatellier G. Value of quantitative radionuclide bone scanning in the diagnosis of sacroiliac joint syndrome in 32 patients with low back pain. Eur Spine J. 1998;7(4):328-331.

62. Eno J-J, Boone C, Bellino M, Bishop J. The prevalence of sacroiliac joint degeneration in asymptomatic adults. $J$ Bone Joint Surg Am. 2015;97(11):932-936. doi:10.2106/JBJS.N.01101

63. Vogler JB, Brown WH, Helms CA, Genant HK. The normal sacroiliac joint: a CT study of asymptomatic patients. Radiology. 1984;151(2):433-437.

64. Cihan OF, Karabulut M, Kılınçoğlu V, Yavuz N. The variations and degenerative changes of sacroiliac joints in asymptomatic adults. Folia Morphol. 2020. doi:10.5603/FM. a2020.0032

65. Fortin J, Dwyer A, West S, Pier J. Sacroiliac joint: pain referral maps upon applying a new injection/arthrography technique. Part I: asymptomatic volunteers. Spine. 1994;19(13):1475-1482.

66. Fortin J, Aprill C, Ponthieux B, Pier J. Sacroiliac joint: pain referral maps upon applying a new injection/arthrography technique. Part II: clinical evaluation. Spine. 1994;19(13):14831489.

67. Kennedy DJ, Engel A, Kreiner DS, Nampiaparampil D, Duszynski B, MacVicar J. Fluoroscopically guided diagnostic and therapeutic intra-articular sacroiliac joint injections: a systematic review. Pain Med Malden Mass. 2015;16(8):1500 1518. doi:10.1111/pme. 12833

68. Jung MW, Schellhas K, Johnson B. Use of diagnostic injections to evaluate sacroiliac joint pain. Int J Spine Surg. 2020;14(Suppl 1):30-34. doi:10.14444/6081

69. Murakami E, Tanaka Y, Aizawa T, Ishizuka M, Kokubun S. Effect of periarticular and intraarticular lidocaine injections for sacroiliac joint pain: prospective comparative study. J Orthop Sci Off J Jpn Orthop Assoc. 2007;12(3):274-280. doi:10.1007/s00776-007-1126-1

70. Kurosawa D, Murakami E, Ozawa H, et al. A diagnostic scoring system for sacroiliac joint pain originating from the posterior ligament. Pain Med Malden Mass. 2016. doi:10.1093/ $\mathrm{pm} / \mathrm{pnw} 117$

71. Broadhurst NA, Bond MJ. Pain provocation tests for the assessment of sacroiliac joint dysfunction. J Spinal Disord. 1998;11(4):341-345.

72. Polly D, Cher D, Whang PG, Frank C, Sembrano J, for 
the INSITE Study Group. Does level of response to SI joint block predict response to SI joint fusion? Int J Spine Surg. 2016;10:article 4. doi:10.14444/3004

73. Cohen SP, Strassels SA, Kurihara C, et al. Outcome predictors for sacroiliac joint (lateral branch) radiofrequency denervation. Reg Anesth Pain Med. 2009;34(3):206-214. doi:10. 1097/AAP.0b013e3181958f4b

74. Cohen SP, Hurley RW, Buckenmaier CC, Kurihara C, Morlando B, Dragovich A. Randomized placebo-controlled study evaluating lateral branch radiofrequency denervation for sacroiliac joint pain. Anesthesiology. 2008;109(2):279-288. doi:10.1097/ALN.0b013e31817f4c7c

75. Patel N, Gross A, Brown L, Gekht G. A randomized, placebo-controlled study to assess the efficacy of lateral branch neurotomy for chronic sacroiliac joint pain. Pain Med. 2012;13(3):383-398. doi:10.1111/j.1526-4637.2012.01328.x

76. Prather H, Hunt D. Sacroiliac joint pain. Dis Mon. 2004;50(12):670-683. doi:10.1016/j.disamonth.2004.12.004

77. Prather $\mathrm{H}$, Bonnette $\mathrm{M}$, Hunt D. Nonoperative treatment options for patients with sacroiliac joint pain. Int $J$ Spine Surg. 2020;14(Suppl 1):35-40. doi:10.14444/6082

78. Neha B, Arunmozhi R, Maneesh A, Pooja A. Effectiveness of therapeutic interventions in sacroiliac joint dysfunction: a systematic review. Int $J$ Physiother Res. 2016;4(3):1484-1488. doi:10.16965/ijpr.2016.111

79. Stuge B, Holm I, Vøllestad N. To treat or not to treat postpartum pelvic girdle pain with stabilizing exercises? Man Ther. 2006;11(4):337-343. doi:10.1016/j.math.2005.07.004

80. Stuge B, Laerum E, Kirkesola G, Vøllestad N. The efficacy of a treatment program focusing on specific stabilizing exercises for pelvic girdle pain after pregnancy: a randomized controlled trial. Spine. 2004;29(4):351-359.

81. Mens JM, Snijders CJ, Stam HJ. Diagonal trunk muscle exercises in peripartum pelvic pain: a randomized clinical trial. Phys Ther. 2000;80(12):1164-1173.

82. Monticone M, Barbarino A, Testi C, Arzano S, Moschi A, Negrini S. Symptomatic efficacy of stabilizing treatment versus laser therapy for sub-acute low back pain with positive tests for sacroiliac dysfunction: a randomised clinical controlled trial with 1 year follow-up. Eur Medicophysica. 2004;40(4):263268.

83. Visser LH, Woudenberg NP, de Bont J, et al. Treatment of the sacroiliac joint in patients with leg pain: a randomizedcontrolled trial. Eur Spine J Off Publ Eur Spine Soc Eur Spinal Deform Soc Eur Sect Cerv Spine Res Soc. 2013;22(10):23102317. doi:10.1007/s00586-013-2833-2

84. Whang PG, Cher D, Polly D, et al. Sacroiliac joint fusion using triangular titanium implants vs. non-surgical management: six-month outcomes from a prospective randomized controlled trial. Int J Spine Surg. 2015;9:article 6. doi:10.14444/ 2006

85. Sturesson B, Kools D, Pflugmacher R, Gasbarrini A, Prestamburgo D, Dengler J. Six-month outcomes from a randomized controlled trial of minimally invasive SI joint fusion with triangular titanium implants vs. conservative management. Eur Spine J. 2017;26(3):708-719. doi:10.1007/ s00586-016-4599-9

86. Juch JNS, Maas ET, Ostelo RWJG, et al. Effect of radiofrequency denervation on pain intensity among patients with chronic low back pain: the Mint randomized clinical trials. JAMA. 2017;318(1):68-81. doi:10.1001/jama.2017.7918

87. Cibulka MT, Delitto A. A comparison of two different methods to treat hip pain in runners. J Orthop Sports Phys Ther. 1993;17(4):172-176.

88. DonTigny RL. Dysfunction of the sacroiliac joint and its treatment. J Orthop Sports Phys Ther. 1979;1(1):23-35.

89. Wreje U, Nordgren B, Åberg H. Treatment of pelvic joint dysfuntion in primary care - a controlled study. Scand $J$ Prim Health Care. 1992;10(4):310-315. doi:10.3109/ 02813439209014080

90. Daly JM, Frame PS, Rapoza PA. Sacroiliac subluxation: a common, treatable cause of low-back pain in pregnancy. Fam Pract Res J. 1991;11(2):149-159.

91. Al-Subahi M, Alayat M, Alshehri MA, et al. The effectiveness of physiotherapy interventions for sacroiliac joint dysfunction: a systematic review. $J$ Phys Ther Sci. 2017;29(9):1689-1694. doi:10.1589/jpts.29.1689

92. Childs JD, Piva SR, Erhard RE. Immediate improvements in side-to-side weight bearing and iliac crest symmetry after manipulation in patients with low back pain. $J$ Manipulative Physiol Ther. 2004;27(5):306-313. doi:10.1016/j.jmpt. 2004.04.004

93. Shearar KA, Colloca CJ, White HL. A randomized clinical trial of manual versus mechanical force manipulation in the treatment of sacroiliac joint syndrome. $J$ Manipulative Physiol Ther. 2005;28(7):493-501. doi:10.1016/j.jmpt.2005.07. 006

94. Kamali F, Shokri E. The effect of two manipulative therapy techniques and their outcome in patients with sacroiliac joint syndrome. J Bodyw Mov Ther. 2012;16(1):29-35. doi:10. 1016/j.jbmt.2011.02.002

95. Barbosa AC, Martins FLM, Barbosa MCSA, dos Santos RT. Manipulation and selective exercises decrease pelvic anteversion and low-back pain: a pilot study. $J$ Back Musculoskelet Rehabil. 2013;26(1):33-36. doi:10.3233/BMR2012-0347

96. Cibulka MT, Delitto A, Koldehoff RM. Changes in innominate tilt after manipulation of the sacroiliac joint in patients with low back pain. Phys Ther. 1988;68(9):1359-1363. doi:10.1093/ptj/68.9.1359

97. Tullberg T, Blomberg S, Branth B, Johnsson R Manipulation does not alter the position of the sacroiliac joint. A roentgen stereophotogrammetric analysis. Spine. 1998;23(10):1124-1128; discussion 1129.

98. Neufeld NJ, Jones JM. Osteopathic Medicine in Musculoskeletal Conditions. In: Gonzalez-Fernandez M, Friedman JD, eds. Physical Medicine and Rehabilitation Pocket Companion. New York, NY: Demos Medical Publishing.; 2011:182-193.

99. Manchikanti L, Hansen H, Pampati V, Falco FJE. Utilization and growth patterns of sacroiliac joint injections from 2000 to 2011 in the medicare population. Pain Physician. 2013;16(4):E379-390.

100. Manchikanti L, Hirsch JA, Pampati V, Boswell MV. Utilization of facet joint and sacroiliac joint interventions in Medicare population from 2000 to 2014: explosive growth continues! Curr Pain Headache Rep. 2016;20(10):58. doi:10. 1007/s11916-016-0588-2

101. Salman OH, Gad SD, Mohamed AA, Rafae, HH, Abdelfatah, AM. Randomized, controlled blind study comparing sacroiliac intra-articular steroid injection to radiofrequency denervation for sacroiliac joint pain. Egypt $J$ Anaesth. 2016;32:219-225. doi:10.1016/j.egja.2015.07.005

102. Dutta K, Dey S, Bhattacharyya P, Agarwal S, Dev P. Comparison of efficacy of lateral branch pulsed radiofrequency 
denervation and intraarticular depot methylprednisolone injection for sacroiliac joint pain. Pain Physician. 2018;21(5):489496.

103. Cánovas Martínez L, Orduña Valls J, Paramés Mosquera E, Lamelas Rodríguez L, Rojas Gil S, Domínguez García M. Sacroiliac joint pain: prospective, randomised, experimental and comparative study of thermal radiofrequency with sacroiliac joint block. Rev Esp Anestesiol Reanim. 2015. doi:10.1016/j.redar.2015.08.003

104. Kim WM, Lee HG, Jeong CW, Kim CM, Yoon MH. A randomized controlled trial of intra-articular prolotherapy versus steroid injection for sacroiliac joint pain. $J$ Altern Complement Med N Y N. 2010;16(12):1285-1290. doi:10.1089/ acm.2010.0031

105. Wehling $\mathrm{P}$, Evans C, Wehling J, Maixner W. Effectiveness of intra-articular therapies in osteoarthritis: a literature review. Ther Adv Musculoskelet Dis. 2017;9(8):183196. doi:10.1177/1759720X17712695

106. Wernecke C, Braun HJ, Dragoo JL. The effect of intraarticular corticosteroids on articular cartilage: a systematic review. Orthop J Sports Med. 2015;3(5):232596711558116. doi: $10.1177 / 2325967115581163$

107. Patel N. Twelve-month follow-up of a randomized trial assessing cooled radiofrequency denervation as a treatment for sacroiliac region pain. Pain Pract. 2016;16(2):154-167. doi:10. 1111/papr.12269

108. Mehta V, Poply K, Husband M, Anwar S, Langford R. The effects of radiofrequency neurotomy using a strip-lesioning device on patients with sacroiliac joint pain: results from a single-center, randomized, sham-controlled trial. Pain Physician. 2018;21(6):607-618.

109. van Tilburg CWJ, Schuurmans FA, Stronks DL, Groeneweg JG, Huygen FJPM. Randomized sham-controlled double-blind multicenter clinical trial to ascertain the effect of percutaneous radiofrequency treatment for sacroiliac joint pain: three-month results. Clin J Pain. 2016. doi:10.1097/AJP. 0000000000000351

110. Maas ET, Juch JNS, Ostelo RWJG, et al. Costeffectiveness of radiofrequency denervation for patients with chronic low back pain: the MINT randomized clinical trials. Value Health J Int Soc Pharmacoeconom Outcomes Res. 2020;23(5):585-594. doi:10.1016/j.jval.2019.12.009

111. Painter CF. Excision of the os innominatum. Arthrodesis of the sacro-iliac synchrondrosis. Boston Med Surg J. 1908;159(7):205-208.

112. McGuire RA, Chen Z, Donahoe K. Dual fibular allograft dowel technique for sacroiliac joint arthrodesis. EvidBased Spine-Care J. 2012;3(3):21-28.

113. Buchowski JM, Kebaish KM, Sinkov V, Cohen DB, Sieber AN, Kostuik JP. Functional and radiographic outcome of sacroiliac arthrodesis for the disorders of the sacroiliac joint. Spine J Off J North Am Spine Soc. 2005;5(5):520-528; discussion 529. doi:10.1016/j.spinee.2005.02.022

114. Belanger TA, Dall BE. Sacroiliac arthrodesis using a posterior midline fascial splitting approach and pedicle screw instrumentation: a new technique. J Spinal Disord. 2001;14(2):118-124.

115. Waisbrod H, Krainick JU, Gerbershagen HU. Sacroiliac joint arthrodesis for chronic lower back pain. Arch Orthop Trauma Surg Arch Für Orthop Unf-Chir. 1987;106(4):238-240.

116. Moore MR. Surgical treatment of chronic painful sacroiliac joint dysfunction. In: Vleeming A, Mooney V, Snijders C, Dorman T, Stoeckart R, eds. Movement, Stability, and Low Back Pain: The Essential Role of the Pelvis. London, England: Churchill Livingstone. 1997:563-572.

117. Graham Smith A, Capobianco R, Cher D, et al. Open versus minimally invasive sacroiliac joint fusion: a multi-center comparison of perioperative measures and clinical outcomes. Ann Surg Innov Res. 2013;7(1):14. doi:10.1186/1750-1164-7-14

118. Sachs D. Minimally invasive versus open sacroiliac joint fusion: a comparison of process measures and description of technique. Conference Proceedings of International Society for the Advancement of Spine Surgery Annual Meeting. 2013:187.

119. Ledonio CGT, Polly DW, Swiontkowski MF. Minimally invasive versus open sacroiliac joint fusion: are they similarly safe and effective? Clin Orthop. 2014;472(6):18311838. doi:10.1007/s11999-014-3499-8

120. Ledonio C, Polly D, Swiontkowski MF, Cummings J. Comparative effectiveness of open versus minimally invasive sacroiliac joint fusion. Med Devices (Auckl). 2014;7:187-193. doi:10.2147/MDER.S60370

121. Avila L. Primary pyogenic infection of the sacro-iliac articulation. A new approach to the joint. J Bone Jt Surg. 1941;23(4):922-928.

122. Rand JA. Anterior sacro-iliac arthrodesis for posttraumatic sacro-iliac arthritis. A case report. J Bone Joint Surg Am. 1985;67(1):157-159.

123. Simpson LA, Waddell JP, Leighton RK, Kellam JF, Tile M. Anterior approach and stabilization of the disrupted sacroiliac joint. J Trauma. 1987;27(12):1332-1339.

124. Nousiainen MT, Weil YA, Helfet DL. Sacroiliac joint arthrodesis. Conference Proceedings Orthopaedic Trauma Association Annual Meeting; 2007;55.

125. Slinkard N, Agel J, Swiontkowski MF. Documentation of outcomes for sacroiliac joint fusion: does prior spinal fusion influence the outcome? Eur Spine J Off Publ Eur Spine Soc Eur Spinal Deform Soc Eur Sect Cerv Spine Res Soc. 2013;22(10):2318-2324. doi:10.1007/s00586-013-2968-1

126. Nystrom B, Gregebo B, Taube A, Almgren S, Schillberg B, Zhu Y. Clinical outcome following anterior arthrodesis in patients with presumed sacroiliac joint pain. Scand J Pain. 2017;17:22-29. doi:10.1016/j.spain.2017.06005

127. Kibsgård TJ, Røise $\mathrm{O}$, Sudmann E, Stuge B. Pelvic joint fusions in patients with chronic pelvic girdle pain: a 23-year follow-up. Eur Spine J. 2013;22(4):871-877. doi:10.1007/ s00586-012-2512-8

128. Kibsgård TJ, Røise $\mathrm{O}$, Stuge $\mathrm{B}$. Pelvic joint fusion in patients with severe pelvic girdle pain - a prospective singlesubject research design study. BMC Musculoskelet Disord. 2014;15:85. doi:10.1186/1471-2474-15-85

129. Murakami E, Kurosawa D, Aizawa T. Sacroiliac joint arthrodesis for chronic sacroiliac joint pain: an anterior approach and clinical outcomes with a minimum 5-year follow-up. J Neurosurg Spine. 2018;29(3):279-285. doi:10. 3171/2018.1.SPINE17115

130. Smith-Petersen MN. Arthrodesis of the sacroiliac joint. A new method of approach. J Bone Joint Surg. 1921;3(8):400405.

131. Smith-Petersen MN, Rogers WA. Arthrodesis for tuberculosis of the sacro-iliac joint. JAMA. 1926;86(1):26-30.

132. Smith-Petersen MN, Rogers WA. End-result study of arthrodesis of the sacro-iliac joint for arthritis - traumatic and non-traumatic. J Bone Joint Surg. 1926;8(1):118-136.

133. Gaenslen FJ. Sacro-iliac arthrodesis: indications, author's technic and end-results. JAMA. 1927;89(24):20312035. 
134. Bloom FA. Sacro-iliac fusion. J Bone Joint Surg. 1937; 19:704-708

135. Schütz U, Grob D. Poor outcome following bilateral sacroiliac joint fusion for degenerative sacroiliac joint syndrome. Acta Orthop Belg. 2006;72(3):296-308.

136. Noureldine MHA, Freeman TB, Alikhani P. Simultaneous sacroiliac joint fusion in patients with long lumbosacral constructs - case report and operative technique. World Neurosurg. 2020. doi:10.1016/j.wneu.2020.04.188

137. Hasan MY, Liu G, Wong H-K, Hao TJ. Post-operative complications of S2AI versus iliac screw in spinopelvic fixation: a meta-analysis and recent trends review. Spine J Off J North Am Spine Soc. 2019. doi:10.1016/j.spinee.2019.11.014

138. Guler UO, Cetin E, Yaman O, et al. Sacropelvic fixation in adult spinal deformity (ASD); a very high rate of mechanical failure. Eur Spine J Off Publ Eur Spine Soc Eur Spinal Deform Soc Eur Sect Cerv Spine Res Soc. 2015;24(5):1085-1091. doi:10.1007/s00586-014-3615-1

139. Colò G, Cavagnaro L, Alessio-Mazzola M, Zanirato A, Felli L, Formica M. Incidence, diagnosis and management of sacroiliitis after spinal surgery: a systematic review of the literature. Musculoskelet Surg. 2019. doi:10.1007/s12306-01900607-0

140. Smith EJ, Kyhos J, Dolitsky R, Yu W, O’Brien J. S2 Alar iliac fixation in long segment constructs, a two- to five-year follow-up. Spine Deform. 2018;6(1):72-78. doi:10.1016/j.jspd. 2017.05.004

141. Mazur MD, Mahan MA, Shah LM, Dailey AT. Fate of S2-alar-iliac screws after 12-month minimum radiographic follow-up: preliminary results. Neurosurgery. 2016:[Epub]. doi:10.1227/NEU.0000000000001322

142. Chang T-L, Sponseller PD, Kebaish KM, Fishman EK. Low profile pelvic fixation: anatomic parameters for sacral alariliac fixation versus traditional iliac fixation. Spine. 2009;34(5):436-440. doi:10.1097/BRS.0b013e318194128c

143. Pham MH, Diaz-Aguilar LD, King BH, Osorio JA, Lehman RA. Quad S2-alar-iliac screw fixation via navigated spinal robotics with software planning: 2-dimensional operative video. Oper Neurosurg Hagerstown Md. 2020. doi:10.1093/ons/ opaa 155

144. Mattei TA, Fassett DR. Combined S-1 and S-2 sacral alar-iliac screws as a salvage technique for pelvic fixation after pseudarthrosis and lumbosacropelvic instability: technical note. J Neurosurg Spine. 2013;19(3):321-330. doi:10.3171/2013.5. SPINE121118

145. Park PJ, Lin JD, Makhni MC, Cerpa M, Lehman RA, Lenke LG. Dual S2 alar-iliac screw technique with a multirod construct across the lumbosacral junction: obtaining adequate stability at the lumbosacral junction in spinal deformity surgery. Neurospine. 2020;17(2):466-470. doi:10.14245/ns. 1938320.160

146. Panico M, Chande RD, Lindsey DP, et al. The use of triangular implants to enhance sacropelvic fixation: a finite element investigation. Spine J Off J North Am Spine Soc. 2020. doi:10.1016/j.spinee.2020.05.552

147. Lorio MP, Polly DW Jr, Ninkovic I, Ledonio CGT, Hallas K, Andersson G. Utilization of minimally invasive surgical approach for sacroiliac joint fusion in surgeon population of ISASS and SMISS membership. Open Orthop J. 2014;8:1-6. doi:10.2174/1874325001408010001

148. Routt MLC, Meier MC, Kregor PJ, Mayo KA. Percutaneous iliosacral screws with the patient supine technique. Oper Tech Orthop. 1993;3(1):35-45.
149. Keating JG, Avillar MD, Price M. Sacroiliac joint arthrodesis in selected patients with low back pain. In: Vleeming A, Mooney V, Snijders C, Dorman T, Stoeckart R, eds. Movement, Stability, and Low Back Pain: The Essential Role of the Pelvis. London, England: Churchill Livingstone. 1997:573-586.

150. Al-Khayer A, Hegarty J, Hahn D, Grevitt MP. Percutaneous sacroiliac joint arthrodesis: a novel technique. $J$ Spinal Disord Tech. 2008;21(5):359-363. doi:10.1097/BSD. 0b013e318145ab96

151. Mason LW, Chopra I, Mohanty K. The percutaneous stabilisation of the sacroiliac joint with hollow modular anchorage screws: a prospective outcome study. Eur Spine J. 2013;22(10):2325-2331. doi:10.1007/s00586-013-2825-2

152. Khurana A, Guha AR, Mohanty K, Ahuja S. Percutaneous fusion of the sacroiliac joint with hollow modular anchorage screws: clinical and radiological outcome. $J$ Bone Joint Surg Br. 2009;91(5):627-631. doi:10.1302/0301-620X. 91B5.21519

153. Frank CJ, Kondrashov D, Meyer SC, et al. Work intensity in sacroiliac joint fusion and lumbar microdiscectomy. Clin Outcomes Res. 2016;8:367-376. doi:10.2147/CEOR. S112006

154. Garber T, Ledonio CGT, Polly DW. How much work effort is involved in minimally invasive sacroiliac joint fusion? Int J Spine Surg. 2015;9:58. doi:10.14444/2058

155. Lorio M, Martinson M, Ferrara L. Paired comparison survey analyses utilizing Rasch methodology of the relative difficulty and estimated work relative value units of CPT $\left({ }^{\circledR}\right)$ code 27279. Int J Spine Surg. 2016;10:40. doi:10.14444/3040

156. Polly DW, Swofford J, Whang PG, et al. Two-year outcomes from a randomized controlled trial of minimally invasive sacroiliac joint fusion vs. non-surgical management for sacroiliac joint dysfunction. Int J Spine Surg. 2016;10:article 28. doi: $10.14444 / 3028$

157. Dengler J, Kools D, Pflugmacher R, et al. Randomized trial of sacroiliac joint arthrodesis compared with conservative management for chronic low back pain attributed to the sacroiliac joint. J Bone Joint Surg Am. 2019;101(5):400-411. doi:10.2106/JBJS.18.00022

158. Duhon BS, Bitan F, Lockstadt H, Kovalsky D, Cher D, Hillen T. Triangular titanium implants for minimally invasive sacroiliac joint fusion: 2-year follow-up from a prospective multicenter trial. Int J Spine Surg. 2016 Apr 20;10:article 13. doi: $10.14444 / 3013$

159. Whang PG, Darr E, Meyer SC, et al. Long-term prospective clinical and radiographic outcomes after minimally invasive lateral transiliac sacroiliac joint fusion using triangular titanium implants. Med Devices (Auckl). 2019 Sep 26;12:411422. doi:10.2147/MDER.S219862

160. Patel V, Kovalsky D, Meyer SC, et al. Prospective trial of sacroiliac joint fusion using 3D-printed triangular titanium implants. Med Devices (Auckl). 2020;13:173-182. doi:10.2147/ MDER.S253741

161. Araghi A, Woodruff R, Colle K, et al. Pain and opioid use outcomes following minimally invasive sacroiliac joint fusion with decortication and bone grafting: the evolusion clinical trial. Open Orthop J. 2017;11(1):1440-1448. doi:10. 2174/1874325001711011440

162. Rappoport LH, Luna IY, Joshua G. Minimally invasive sacroiliac joint fusion using a novel hydroxyapatitecoated screw: preliminary 1-year clinical and radiographic 
results of a 2-year prospective study. World Neurosurg. 2017;101:493-497. doi:10.1016/j.wneu.2017.02.046

163. Dengler J, Duhon B, Whang P, et al. Predictors of outcome in conservative and minimally invasive surgical management of pain originating from the sacroiliac joint: a pooled analysis. Spine. 2017;42(21):1664-1673. doi:10.1097/ BRS.0000000000002169

164. Spain K, Holt T. Surgical revision after sacroiliac joint fixation or fusion. Int J Spine Surg. 2017;11:24-30. doi:10. $14444 / 4005$

165. Vanaclocha V, Herrera JM, Sáiz-Sapena N, Rivera-Paz M, Verdú-López F. Minimally invasive sacroiliac joint fusion, radiofrequency denervation, and conservative management for sacroiliac joint pain: 6-year comparative case series. Neurosurgery. 2018;82(1):48-55. doi:10.1093/neuros/nyx185

166. Claus CF, Lytle E, Kaufmann A, et al. Minimally invasive sacroiliac joint fusion using triangular titanium vs. cylindrical threaded implants: a comparison of patient-reported outcomes. World Neurosurg. 2019. doi:10.1016/j.wneu.2019.09. 150

167. Abbasi H, Hipp JA. The assessment of fusion following sacroiliac joint fusion surgery. Cureus. 2017;9(10):e1787. doi:10. $7759 /$ cureus. 1787

168. Rajpal S, Burneikiene S. Minimally invasive sacroiliac joint fusion with cylindrical threaded implants using intraoperative stereotactic navigation. World Neurosurg. 2018. doi:10. 1016/j.wneu.2018.11.116

169. Kancherla VK, McGowan SM, Audley BN, Sokunbi G, Puccio ST. Patient reported outcomes from sacroiliac joint fusion. Asian Spine J. 2017;11(1):120-126. doi:10.4184/asj.2017. 11.1.120

170. Sachs D, Capobianco R. Minimally invasive sacroiliac joint fusion: one-year outcomes in 40 patients. Adv Orthop. 2013;2013:536128. doi:10.1155/2013/536128

171. Sachs D, Kovalsky D, Redmond A, et al. Durable intermediate- to long-term outcomes after minimally invasive transiliac sacroiliac joint fusion using triangular titanium implants. Med Devices (Auckl). 2016;9:213-222. doi:10.2147/ MDER.S109276

172. Sachs D, Capobianco R, Cher D, et al. One-year outcomes after minimally invasive sacroiliac joint fusion with a series of triangular implants: a multicenter, patient-level analysis. Med Devices (Auckl). 2014;7:299-304. doi:10.2147/ MDER.S56491

173. Cummings J Jr, Capobianco RA. Minimally invasive sacroiliac joint fusion: one-year outcomes in 18 patients. Ann Surg Innov Res. 2013;7(1):1-7. doi:10.1186/1750-1164-7-12

174. Schroeder JE, Cunningham ME, Ross T, Boachie-Adjei O. Early results of sacro-iliac joint fixation following long fusion to the sacrum in adult spine deformity. Hosp Spec Surg J. 2013;10(1):30-35. doi:10.1007/s11420-013-9374-4

175. Gaetani P, Miotti D, Risso A, et al. Percutaneous arthrodesis of sacro-iliac joint: a pilot study. J Neurosurg Sci. 2013;57(4):297-301.

176. Rudolf L. Sacroiliac joint arthrodesis-MIS technique with titanium implants: report of the first 50 patients and outcomes. Open Orthop J. 2012;6:495-502. doi:10.2174/ 1874325001206010495

177. Kim J, Rudolf L, Glaser J. Outcome of percutaneous sacroiliac joint fixation with porous plasma coated titanium implants: an independent review. Open Orthop J. 2013;7:51-56.

178. Rudolf L, Capobianco R. Five-year clinical and radiographic outcomes after minimally invasive sacroiliac joint fusion using triangular implants. Open Orthop J. 2014;8:375383. doi: $10.2174 / 1874325001408010375$

179. Bornemann R, Roessler PP, Strauss AC, et al. Twoyear clinical results of patients with sacroiliac joint syndrome treated by arthrodesis using a triangular implant system. Technol Health Care. 2017;25(2):319-325. doi:10.3233/THC161272

180. Rainov NG, Schneiderhan R, Heidecke V. Triangular titanium implants for sacroiliac joint fusion. Eur Spine J Off Publ Eur Spine Soc Eur Spinal Deform Soc Eur Sect Cerv Spine Res Soc. 2018. doi:10.1007/s00586-018-5860-1

181. Cleveland A, Nhan D, Akiyama M, Kleck C, Noshchenko A, Patel V. Mini-open sacroiliac joint fusion with direct bone grafting and minimally invasive fixation using intraoperative navigation. J Spine Surg. 2019;5(1):31-37. doi: $10.21037 /$ jss.2019.01.04

182. Mao G, Aldahak N, Kusyk D, et al. A consideration for the utility of the post-operative Oswestry Disability Index for measuring outcomes after sacroiliac joint fusion. Orthop Rev. 2018;10(2):7549. doi:10.4081/or.2018.7549

183. Vanaclocha-Vanaclocha V, Verdú-López F, SánchezPardo M, et al. Minimally invasive sacroiliac joint arthrodesis: experience in a prospective series with 24 patients. J Spine. 2014;3:185. doi:10.4172/2165-7939.1000185

184. Cross WW, Delbridge A, Hales D, Fielding LC. Minimally invasive sacroiliac joint fusion: 2-year radiographic and clinical outcomes with a principles-based SIJ fusion system. Open Orthop J. 2018;12(1):7-16. doi:10.2174/ 1874325001812010007

185. Kube RA, Muir JM. Sacroiliac joint fusion: one year clinical and radiographic results following minimally invasive sacroiliac joint fusion surgery. Open Orthop J. 2016;10:679-689. doi:10.2174/1874325001610010679

186. Heiney J, Capobianco R, Cher D. A systematic review of minimally invasive sacroiliac joint fusion utilizing a lateral transarticular technique. Int J Spine Surg. 2015 Jul 22;9:article 40. doi:10.14444/2040

187. Lingutla KK, Pollock R, Ahuja S. Sacroiliac joint fusion for low back pain: a systematic review and meta-analysis. Eur Spine J. 2016;25(6):1924-1931. doi:10.1007/s00586-0164490-8

188. Tran ZV, Ivashchenko A, Brooks L. Sacroiliac joint fusion methodology - minimally invasive compared to screwtype surgeries: a systematic review and meta-analysis. Pain Physician. 2019;22(1):29-40.

189. Zaidi HA, Montoure AJ, Dickman CA. Surgical and clinical efficacy of sacroiliac joint fusion: a systematic review of the literature. J Neurosurg Spine. 2015;23(1):59-66. doi:10.3171/ 2014.10.SPINE14516

190. Whelan R, Duhon B. The evidence for sacroiliac joint surgery. Tech Orthop. 2019;34(2):87-95. doi:10.1097/BTO. 0000000000000367

191. Shamrock AG, Patel A, Alam M, Shamrock KH, Al Maaieh M. The safety profile of percutaneous minimally invasive sacroiliac joint fusion. Glob Spine J. 2019:2192568218816981. doi: $10.1177 / 2192568218816981$

192. Yson SC, Sembrano JN, Polly DW. Sacroiliac joint fusion: approaches and recent outcomes. $P M$ R. 2019. doi:10. 1002/pmrj.12198

193. Martin CT, Haase L, Lender PA, Polly DW. Minimally invasive sacroiliac joint fusion: the current evidence. Int J Spine Surg. 2020;14(Suppl 1):20-29. doi:10.14444/6072

194. Schoell K, Buser Z, Jakoi A, et al. Postoperative 
complications in patients undergoing minimally invasive sacroiliac fusion. Spine J. 2016 Nov;16(11)1324-1332. doi:10. 1016/j.spinee.2016.06.016

195. Miller L, Reckling WC, Block JE. Analysis of postmarket complaints database for the iFuse SI Joint Fusion System: a minimally invasive treatment for degenerative sacroiliitis and sacroiliac joint disruption. Med Devices (Auckl). 2013 May 29;6:77-84. doi:10.2147/MDER.S44690

196. Cher DJ, Reckling WC, Capobianco RA. Implant survivorship analysis after minimally invasive sacroiliac joint fusion using the iFuse Implant System. Med Devices (Auckl). 2015 Nov 23;8:485-492. doi:10.2147/MDER.S94885

197. Cher D, Wroe K, Reckling WC, Yerby S. Postmarket surveillance of 3D-printed implants for sacroiliac joint fusion. Med Devices (Auckl). 2018 Sep 28;11:337-343. doi:10.2147/ MDER.S180958

198. Kiapour A, Joukar A, Elgafy H, Erbulut DU, Agarwal AK, Goel VK. Biomechanics of the sacroiliac joint: anatomy, function, biomechanics, sexual dimorphism, and causes of pain. Int J Spine Surg. 2020;14(Suppl 1):3-13. doi:10.14444/6077

199. Casaroli G, Bassani T, Brayda-Bruno M, Luca A, Galbusera F. What do we know about the biomechanics of the sacroiliac joint and of sacropelvic fixation? A literature review. Med Eng Phys. 2019. doi:10.1016/j.medengphy.2019.10.009

200. Lindsey D, Perez-Orribo L, Rodriquez-Martinez N, et al. Evaluation of a minimally invasive procedure for sacroiliac joint fusion - an in vitro biomechanical analysis of initial and cycled properties. Med Devices (Auckl). 2014 May 15;7:131137. doi:10.2147/MDER.S63499

201. Lindsey DP, Kiapour A, Yerby SA, Goel VK. Sacroiliac joint stability: finite element analysis of implant number, orientation, and superior implant length. World $J$ Orthop. 2018;9(3):14-23. doi:10.5312/wjo.v9.i3.14

202. Soriano-Baron H, Lindsey DP, Rodriguez-Martinez N, et al. The effect of implant placement on sacroiliac joint range of motion: posterior vs trans-articular. Spine. 2015;40(9):E525E530. doi:10.1097/BRS.0000000000000839

203. Bruna-Rosso C, Arnoux P-J, Bianco R-J, GodioRaboutet Y, Fradet L, Aubin C-É. Finite element analysis of sacroiliac joint fixation under compression loads. Int J Spine Surg. 2016;10:article 16. doi:10.14444/3016

204. Shih YC, Beaubien BP, Chen Q, Sembrano JN. Biomechanical evaluation of sacroiliac joint fixation with decortication. Spine J. 2018;18(7):1241-1249. doi:10.1016/j. spinee.2018.02.016

205. Cross WW, Berven SH, Slater N, Lehrman JN, Newcomb AGUS, Kelly BP. In vitro biomechanical evaluation of a novel, minimally invasive, sacroiliac joint fixation device. Int J Spine Surg. 2018 Oct 15;12(5):587-594. doi:10.14444/5072

206. Dubé-Cyr R, Aubin C-E, Villemure I, Bianco R-J, Godio-Raboutet Y, Arnoux P-J. Biomechanical analysis of two insertion sites for the fixation of the sacroiliac joint via an oblique lateral approach. Clin Biomech (Bristol Avon). 2020 Apr;74:118-123. doi:10.1016/j.clinbiomech.2020.02.010

207. Lindsey D, Kiapour A, Gundanna M, Leasure J, Yerby SA, Kondroshov D. Biomechanics of unilateral and bilateral sacroiliac jloint stabilization: laboratory investigation. $J$ Neurosurg Spine. 2018;28(3):326-332. doi:10.3171/2017.7. SPINE17499.

208. Lindsey DP, Kiapour A, Yerby SA, Goel VK. Sacroiliac joint fusion minimally affects adjacent lumbar segment motion: a finite element study. Int J Spine Surg. 2015 Nov 13;9:64. doi:10.14444/2064
209. Joukar A, Chande RD, Carpenter RD, et al. Effects on hip stress following sacroiliac joint fixation: a finite element study. JOR Spine. 2019;2(4):e1067. doi:10.1002/jsp2.1067

210. Cher DJ, Frasco MA, Arnold RJ, Polly DW. Costeffectiveness of minimally invasive sacroiliac joint fusion. Clinicoecon Outcomes Res. 2015 Dec 18;8:1-14. doi:10.2147/ CEOR.S94266

211. Ackerman SJ, Polly DW Jr, Knight T, Holt T, Cummings J Jr. Nonoperative care to manage sacroiliac joint disruption and degenerative sacroiliitis: high costs and medical resource utilization in the United States Medicare population. $J$ Neurosurg Spine. 2014;20(4):354-363. doi:10.3171/2014.1. SPINE13188

212. Ackerman S, Polly DW, Holt T, Cummings JT, Knight T. Management of sacroiliac joint disruption and degenerative sacroiliitis with nonoperative care is medical resource-intensive and costly in a United States commercial payer population. Clin Outcomes Res. 2014;2014(6):63-74. doi:10.2147/CEOR.S54158

213. Ackerman S, Cummings J, Polly D, Knight T, Schneider K, Holt T. Comparison of the costs of nonoperative care to minimally invasive surgery for sacroiliac joint disruption and degenerative sacroiliitis in a United States Medicare population: potential economic implications of a new minimally-invasive technology. Clin Outcomes Res. 2013;2013(5):575587. doi:10.2147/CEOR.S52967

214. Ackerman S, Knight $\mathrm{T}$, Schneider $\mathrm{K}$, Holt $\mathrm{T}$, Cummings J, Polly D. Comparison of the costs of nonoperative care to minimally invasive surgery for sacroiliac joint disruption and degenerative sacroiliitis in a United States commercial payer population: potential economic implications of a new minimally invasive technology. Clin Outcomes Res. 2014;2014(6):283-296. doi:10.2147/CEOR.S63757

215. Lorio MP. ISASS Policy 2016 update-minimally invasive sacroiliac joint fusion. Int J Spine Surg. 2016;10:26. doi: $10.14444 / 3026$

216. Lekovic GP, Han PP, Kenny KJ, Dickman CA. Bone dowels in anterior lumbar interbody fusion. J Spinal Disord Tech. 2007;20(5):374-379. doi:10.1097/BSD.0b013e31802c1462

217. Kuslich SD. The Bagby and Kuslich method of lumbar interbody fusion. Spine. 1998;23(11):1267-1279. doi:10.1097/ 00007632-199806010-00019

218. Kuslich SD, Danielson G, Dowdle JD, et al. Four-year follow-up results of lumbar spine arthrodesis using the Bagby and Kuslich lumbar fusion cage. Spine. 2000;25(20):2656-2662. doi:10.1097/00007632-200010150-00018

219. Button G, Gupta M, Barrett C, Cammack P, Benson D. Three- to six-year follow-up of stand-alone BAK cages implanted by a single surgeon. Spine J. 2005;5(2):155-160. doi:10.1016/j.spinee.2004.06.021

220. Wise CL, Dall BE. Minimally invasive sacroiliac arthrodesis: outcomes of a new technique. J Spinal Disord Tech. 2008;21(8):579-584. doi:10.1097/BSD.0b013e31815ecc4b

221. Endres S, Ludwig E. Outcome of distraction interference arthrodesis of the sacroiliac joint for sacroiliac arthritis. Indian J Orthop. 2013;47(5):437-442. doi:10.4103/0019-5413. 118197

222. Fuchs V, Ruhl B. Distraction arthrodesis of the sacroiliac joint: 2-year results of a descriptive prospective multi-center cohort study in 171 patients. Eur Spine J. 2018;27(1):194-204. doi:10.1007/s00586-017-5313-2

223. Stark JG, Brown GA, Idemmili C, Meyer CL. Fusion of the sacroiliac joint: new technique and functional outcome. 
In: Conference Proceedings American Academy of Orthopaedic Surgeons Annual Meeting. 2008.

224. Morningstar. Make a case for unlisted codes. $A A P C$ Healthc Bus Mon. 2020;42(3). https://www.aapc.com/?\&utm_ medium $=$ p pc \&utm_source $=$ adwords $\&$ utm_ter $m=\%$ 2Baapc\&utm_campaign=Search_Google_Brand_AAPC-Core_ BMM\&hsa_cam=6492563276\&hsa_tgt=aud-412910490190:kwd$312940333590 \& h s a \_k w=\% 2 B a a p c \& h s a \_v e r=3 \& h s a$ ad $=426824$ $675943 \&$ hsa_acc $=8669576186 \&$ hsa_grp $=76662609503 \&$ hsa_ $\mathrm{src}=\mathrm{g} \& \mathrm{hsa}$ _net $=$ adwords\&hsa_mt $=\mathrm{b} \& \mathrm{gclid}=\mathrm{CjwKCAjw}$ NX7BRA1EiwA2dpg0pXUiVqSSj54Vvxu-FZROgzvUz5Id9 srHQB7y7wwb2A0rzjOgd6WVBoCJQIQAvD_BwE\&gclsre=aw. ds. Accessed on September 28, 2020.

225. Dengler J, Kools D, Pflugmacher R, et al. 1-year results of a randomized controlled trial of conservative management vs. minimally invasive surgical treatment for sacroiliac joint pain. Pain Physician. 2017;20(6):537-550.

226. Polly DW, Cher DJ, Wine KD, et al. Randomized controlled trial of minimally invasive sacroiliac joint fusion using triangular titanium implants vs nonsurgical management for sacroiliac joint dysfunction: 12-month outcomes. Neurosurgery. 2015;77(5):674-691. doi:10.1227/NEU.0000000000000988

227. Darr E, Cher D. 4-Year outcomes after minimally invasive transiliac sacroiliac joint fusion with triangular titanium implants. Med Devices (Auckl). 2018 Aug 29;11:287-289. doi:10.2147/MDER.S179003

228. Darr E, Meyer SC, Whang PG, et al. Long-term prospective outcomes after minimally invasive trans-iliac sacroiliac joint fusion using triangular titanium implants. Med Devices (Auckl). 2018 Apr 9;11:113-121. doi:10.2147/MDER. $\mathrm{S} 160989$

229. Patel V, Kovalsky D, Meyer SC, et al. Minimally invasive lateral transiliac sacroiliac joint fusion using 3Dprinted triangular titanium implants. Med Devices Evid Res. 2019;12:203-214. doi:10.2147/MDER.S205812

230. Duhon BS, Cher DJ, Wine KD, Kovalsky DA, Lockstadt H, on behalf of the SIFI Study Group. Triangular titanium implants for minimally invasive sacroiliac joint fusion: a prospective study. Glob Spine J. 2016;6(3):257-269. doi:10. 1055/s-0035-1562912

\section{APPENDIX}

Table A1. ICD-10-CM diagnosis codes and descriptions.

\begin{tabular}{|c|c|}
\hline $\begin{array}{l}\text { ICD-10-CM } \\
\text { Diagnosis Code }\end{array}$ & Code Descriptor \\
\hline M46.1 & Sacroiliitis, not elsewhere classified \\
\hline M53.2x8 & Spinal instabilities, sacral and sacrococcygeal region \\
\hline M53.3 & Disorders of sacrum \\
\hline S $33.2 \times x A$ & Dislocation of sacroiliac and sacrococcygeal joint \\
\hline S33.6xxA & Sprain of sacroiliac joint \\
\hline 099.89 & $\begin{array}{l}\text { Other specified diseases and conditions complicating } \\
\text { pregnancy, childbirth, and the puerperium }\end{array}$ \\
\hline 094 & $\begin{array}{l}\text { Sequelae of complication of pregnancy, childbirth, } \\
\text { and the puerperium }\end{array}$ \\
\hline
\end{tabular}

Abbreviation: ICD-10-CM, International Classification of Diseases, Tenth Revision, Clinical Modification.
231. Duhon BS, Cher DJ, Wine KD, Lockstadt H, Kovalsky D, Soo C-L. Safety and 6-month effectiveness of minimally invasive sacroiliac joint fusion: a prospective study. Med Devices (Auckl). 2013 Dec 13;6:219-229. doi:10.2147/MDER. S55197

232. Capobianco R, Cher D, SIFI Study Group. Safety and effectiveness of minimally invasive sacroiliac joint fusion in women with persistent post-partum posterior pelvic girdle pain: 12-month outcomes from a prospective, multi-center trial. SpringerPlus. 2015 Oct 5;4:570. doi:10.1186/s40064-015-1359-y

233. Sachs D, Capobianco R. One year successful outcomes for novel sacroiliac joint arthrodesis system. Ann Surg Innov Res. 2012;6(1):13. doi:10.1186/1750-1164-6-13

234. Bornemann R, Pflugmacher R, Webler M, et al. Clinical trial to test the iFuse implant system ${ }^{\circledR}$ in patients with sacroiliac joint syndrome: one year results [in German]. Z Orthopadie Unfallchirurgie. 2016;154(6):601-605. doi:10.1055/s-0042110207

235. Rudolf L. MIS Fusion of the SI joint: does prior lumbar spinal fusion affect patient outcomes? Open Orthop J. 2013;7:163-168. doi:10.2174/1874325001307010163

Disclosures and COI: The authors received no funding for this update; ML - SAB Vivex Biologics; RK - no COI; AA - Consultant Surgalign.

Corresponding Author: Morgan Lorio, MD, Advanced Orthopedics, 499 East Central Parkway, Altamonte Springs, FL 32701. Phone: (407) 960-1717; Email: mloriomd@gmail.com.

Published 22 January 2021

This manuscript is generously published free of charge by ISASS, the International Society for the Advancement of Spine Surgery. Copyright (c) 2020 ISASS. To see more or order reprints or permissions, see http://ijssurgery.com. 


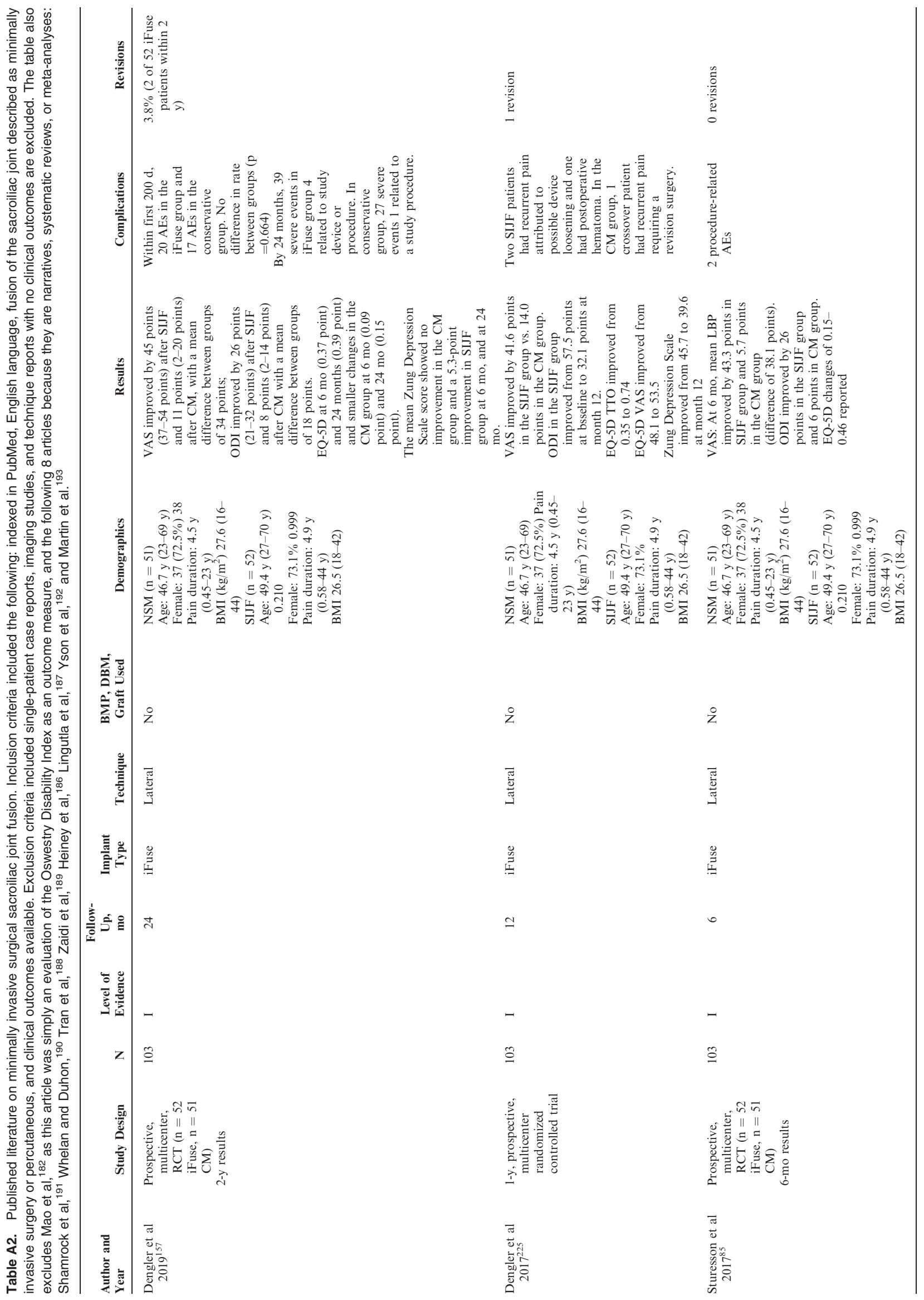




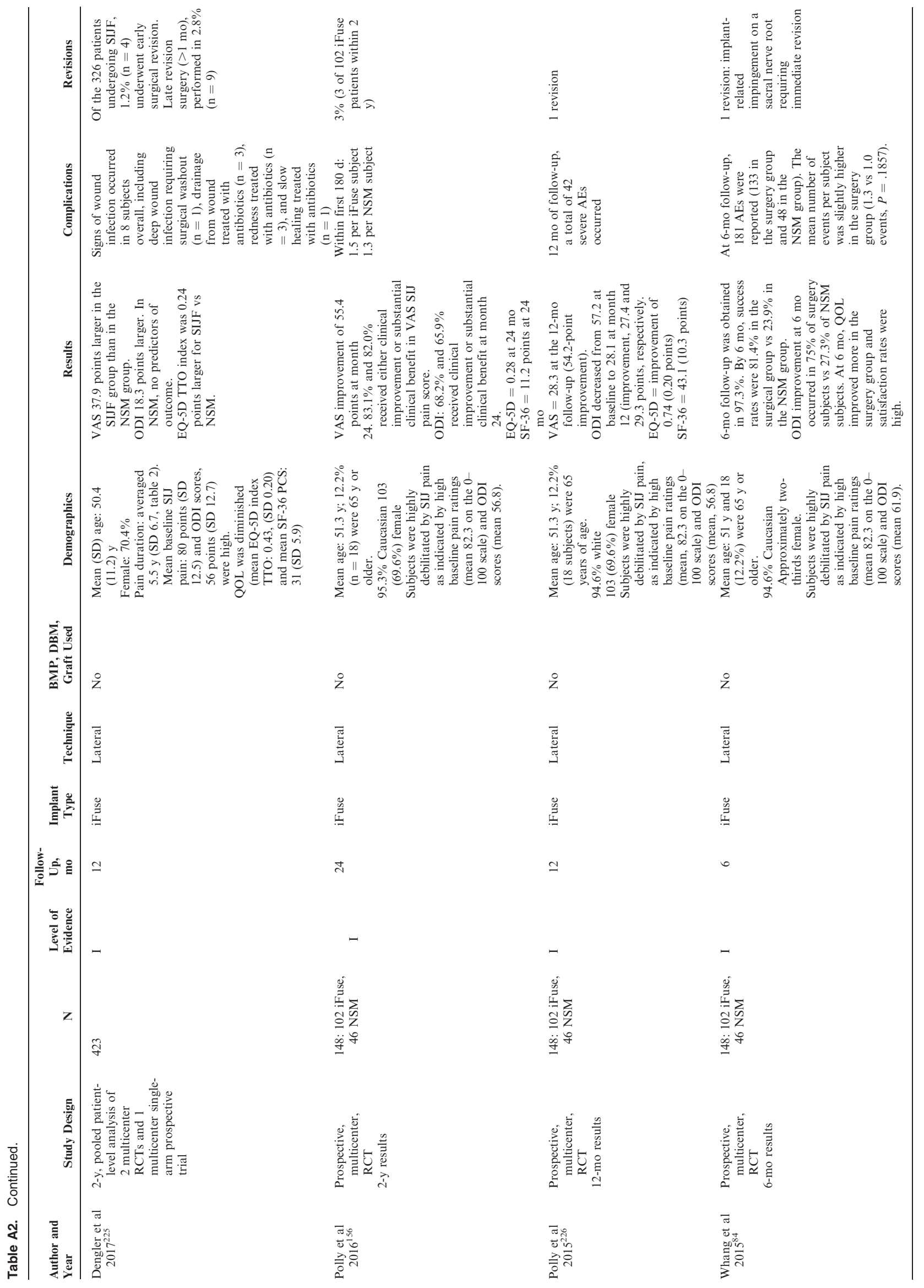




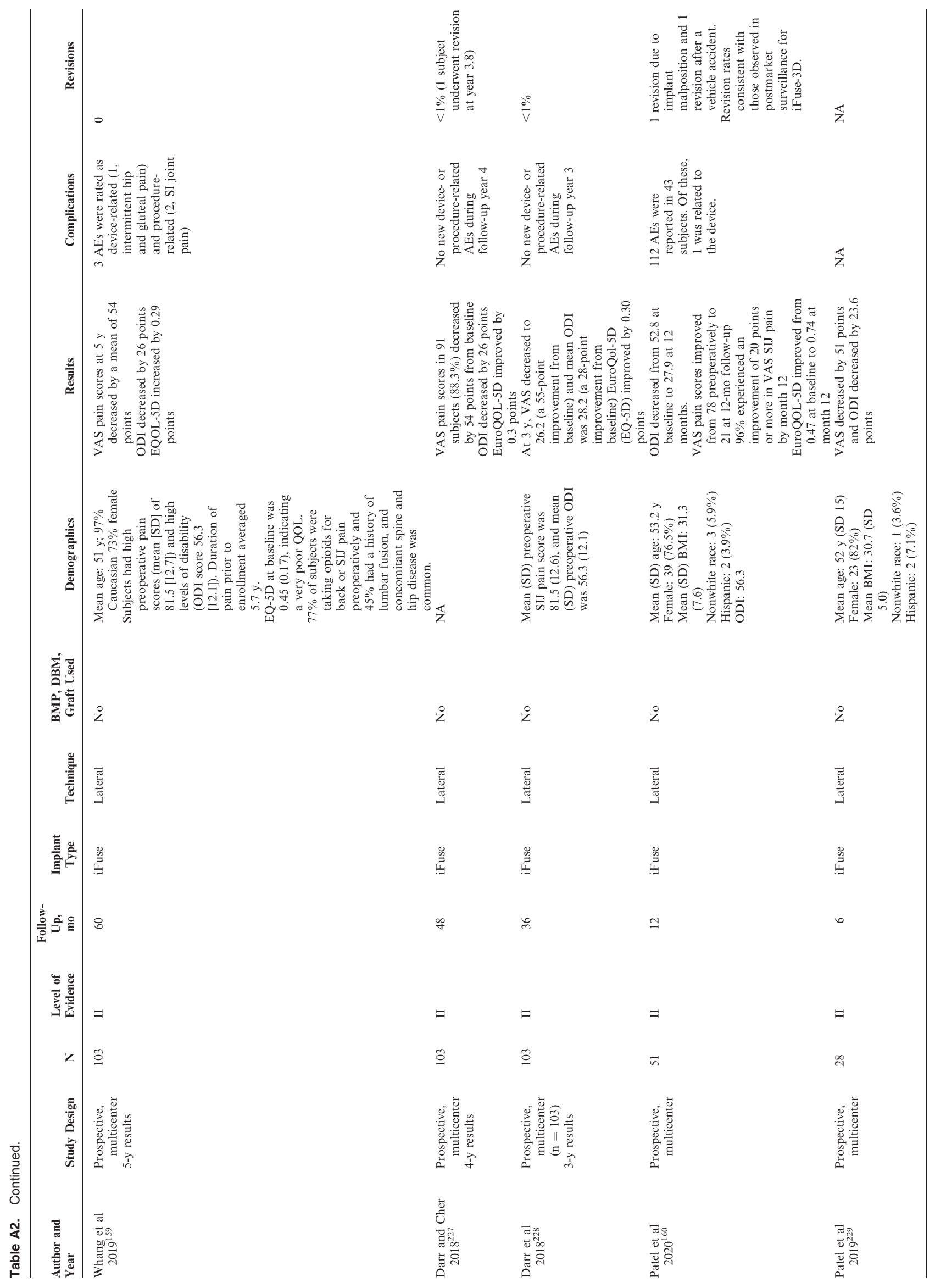


Lorio et al.

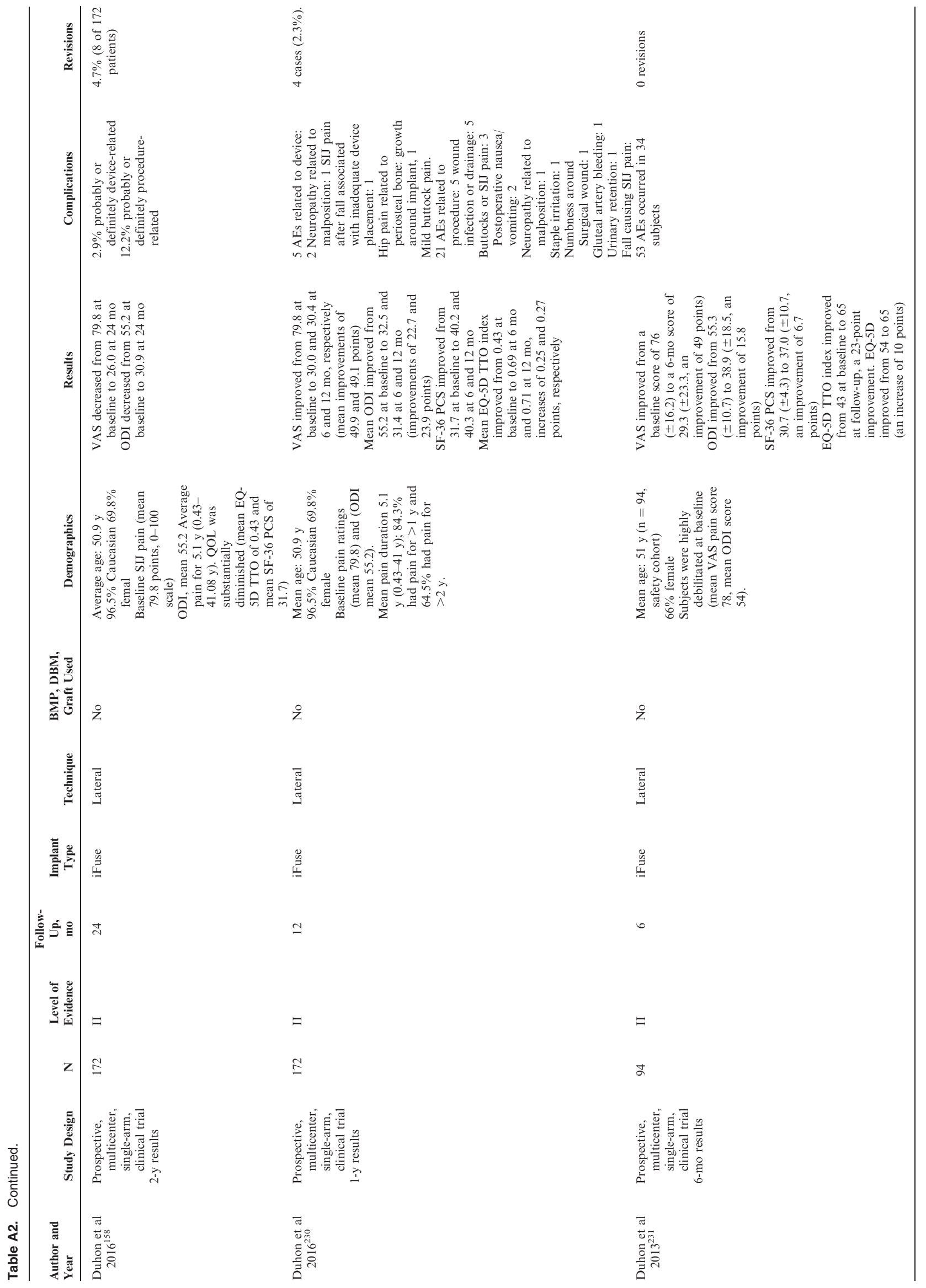




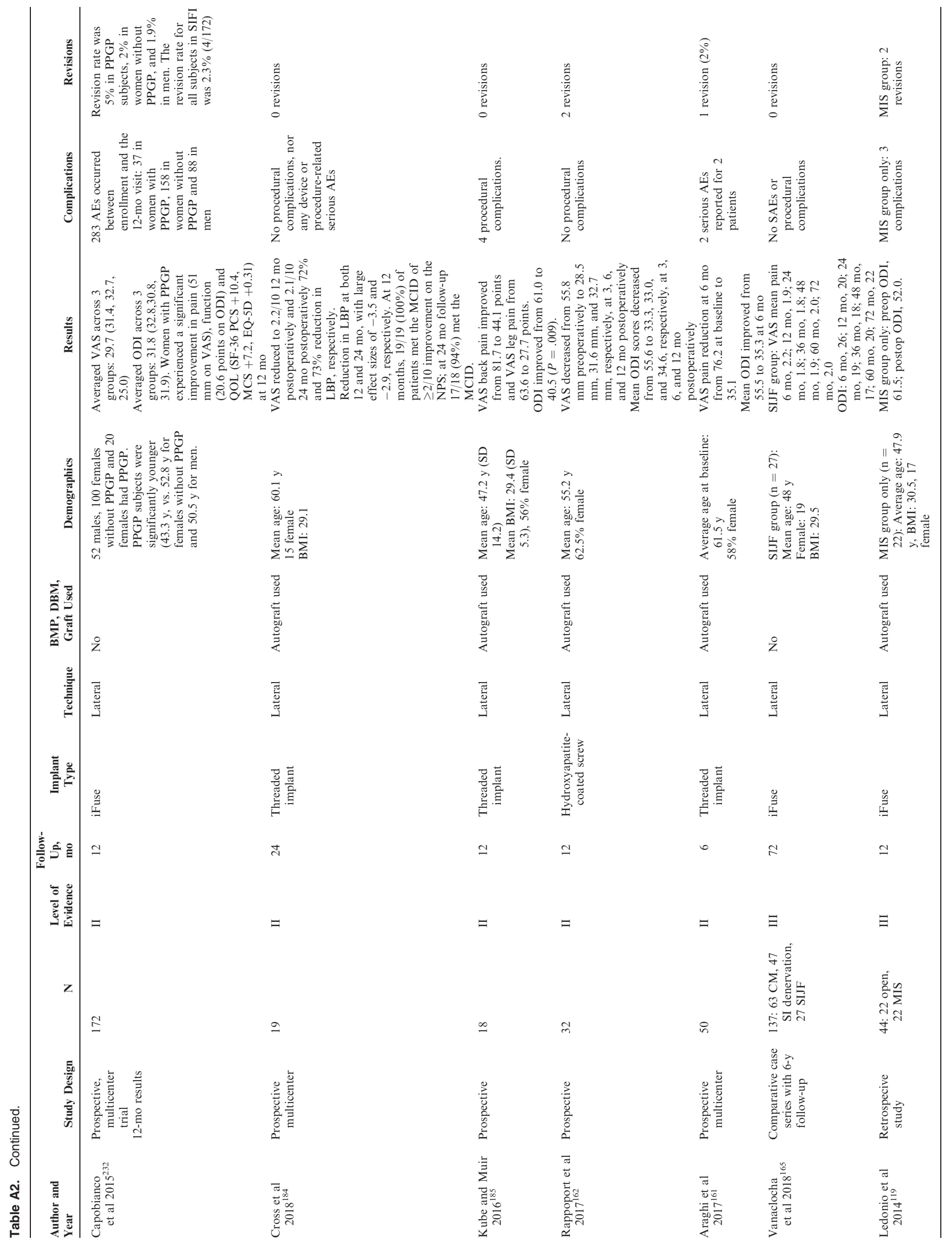




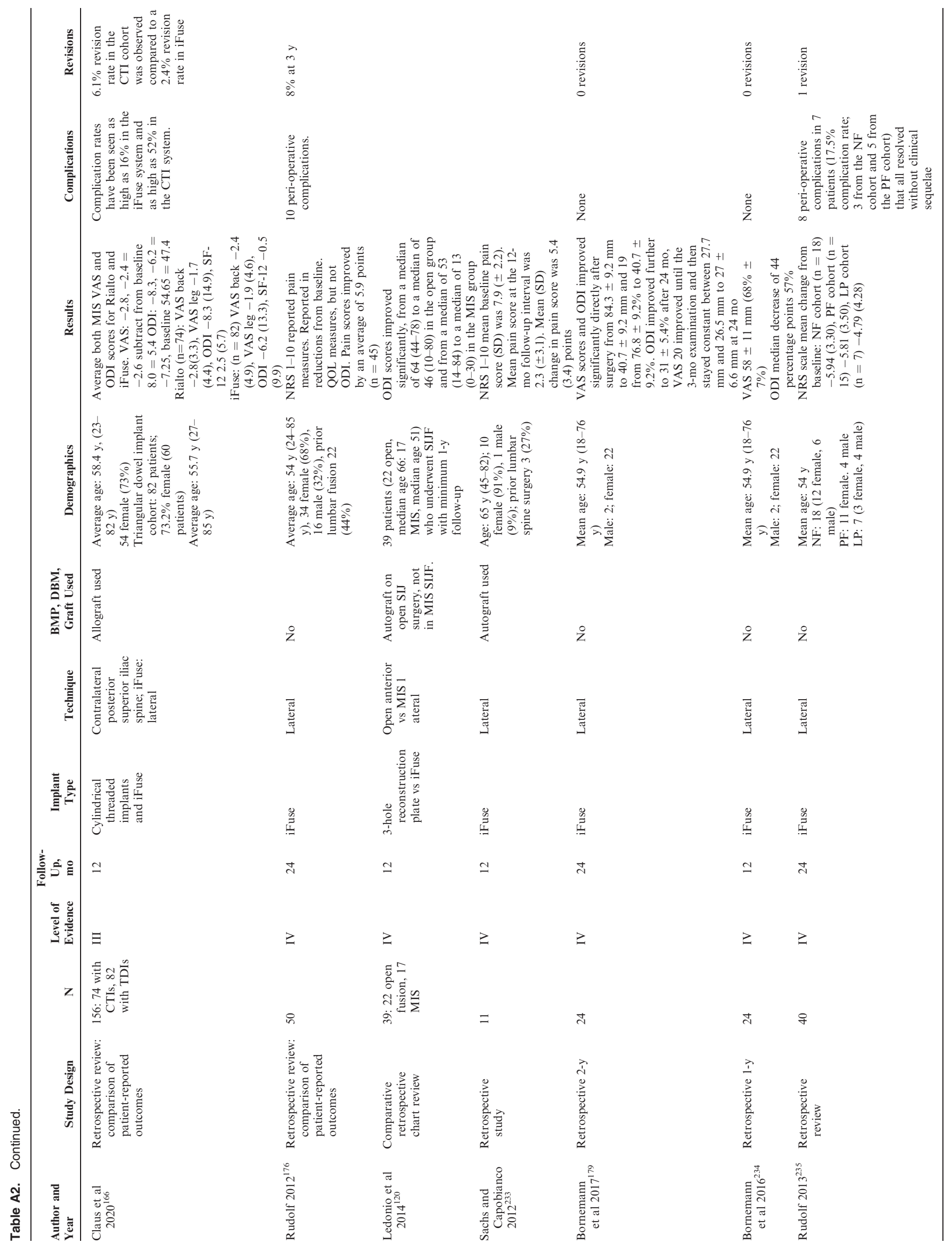




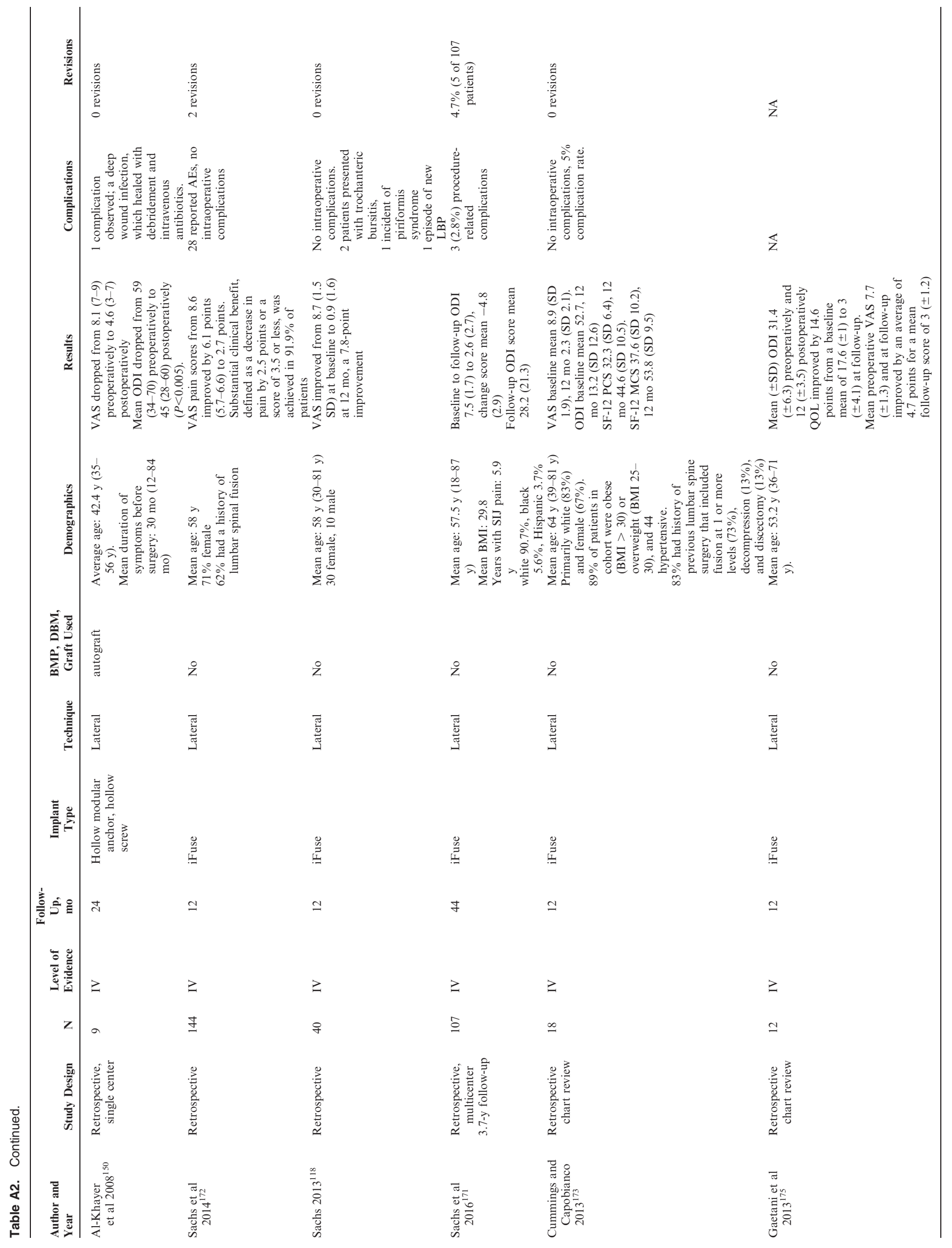




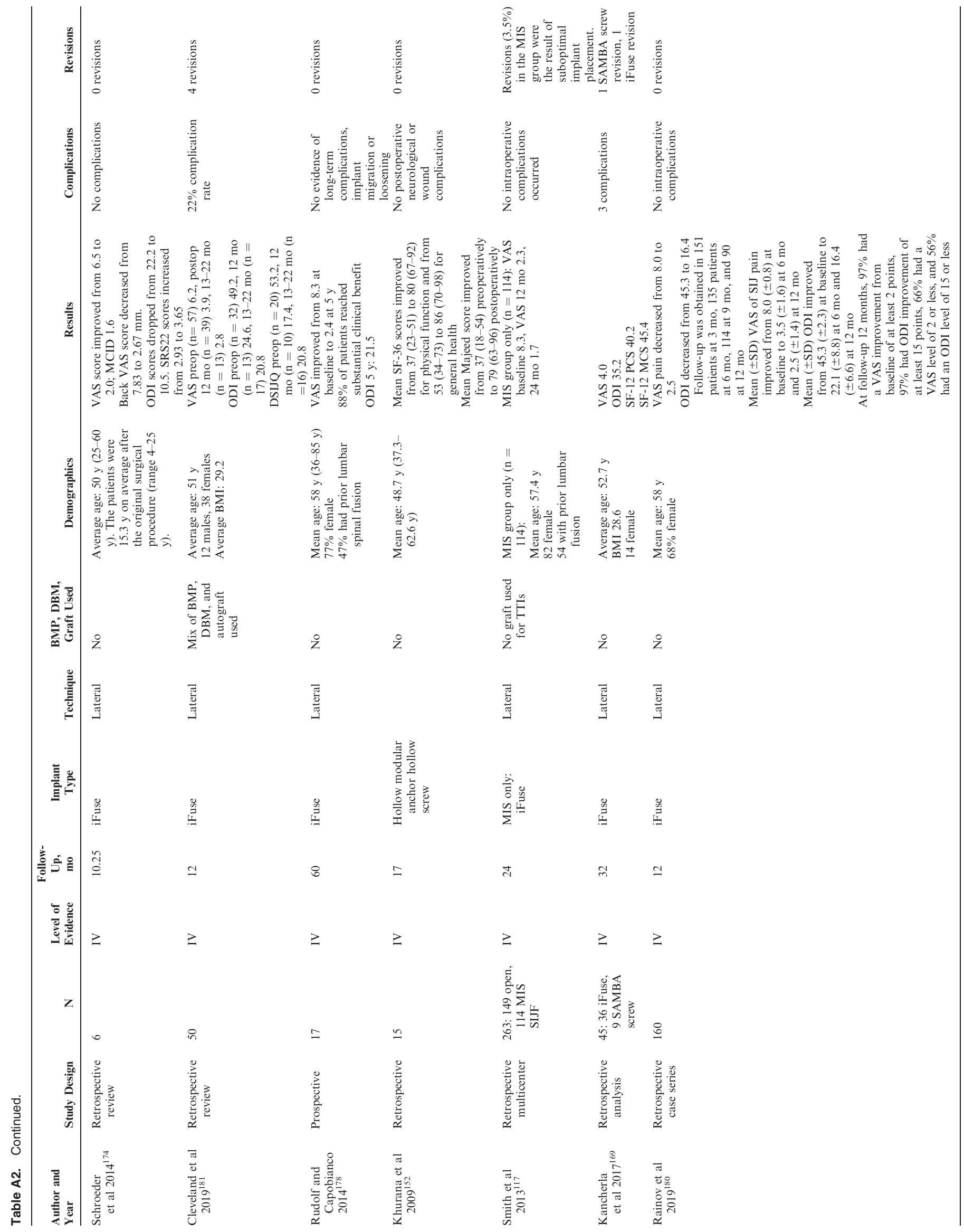




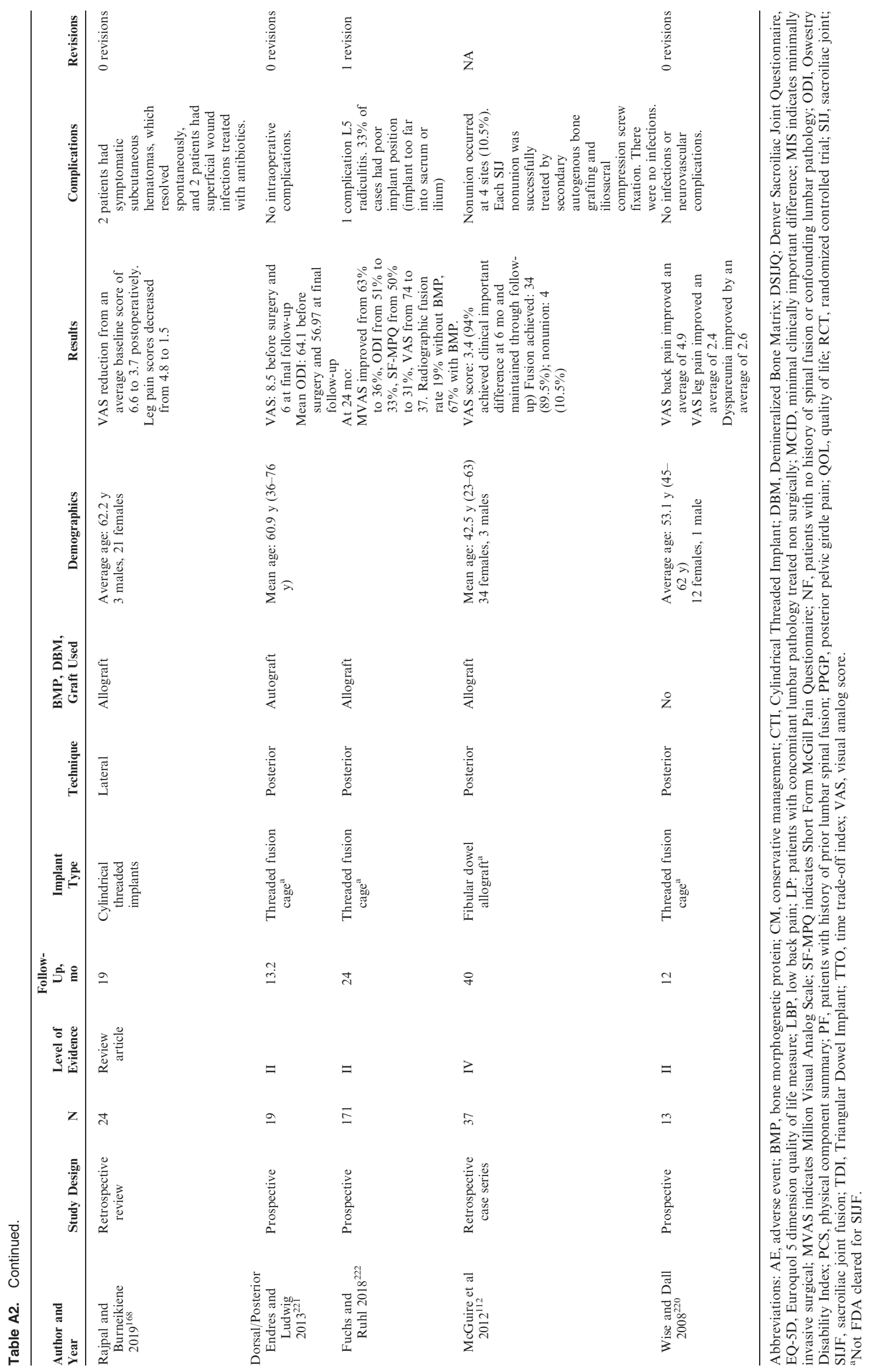



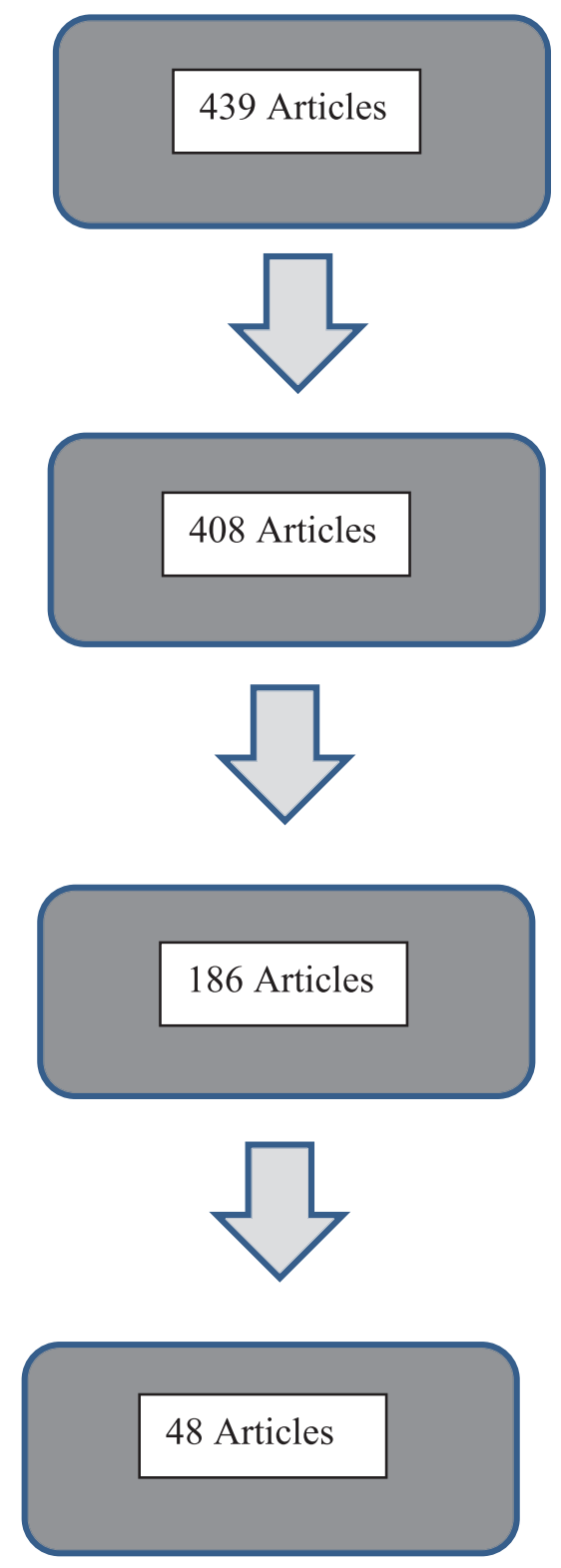

Figure A1. Literature search exclusions flow chart. The flow chart excludes the following 8 articles; narrative, systematic reviews, and meta-analyses: Shamrock Global Spine Journal - 2019: The safety profile of percutaneous minimally invasive sacroiliac joint fusion. ${ }^{191}$; Whelan - Techniques in Orthopaedics - 2019: The evidence for sacroiliac joint surgery. ${ }^{190}$; Tran - Pain Physician - 2019: Sacroiliac joint fusion methodology-minimally invasive compared to screw-type surgeries: a systematic review and meta analysis. ${ }^{188}$; Zaidi - J Neurosurg Spine 2015: Surgical and clinical efficacy of sacroiliac joint fusion: a systematic review of the literature. ${ }^{189}$; Heiney - Int J Spine Surg 2015: A systematic review of minimally invasive sacroiliac joint fusion utilizing a lateral transarticular technique. ${ }^{186}$; Lingutla Eur Spine J 2016: Sacroiliac joint fusion for low back pain: a systematic review and meta-analysis. ${ }^{187}$; Yson - PM R 2019: Sacroiliac joint fusion: approaches and recent outcomes. Published online. ${ }^{192}$; Martin - Int J Spine Surg. 2020: Minimally invasive sacroiliac joint fusion: the current evidence. ${ }^{193}$ Also excludes: Mao A Orthop Rev (Pavia) 2018: A Consideration for the utility of the post-operative Oswestry Disability Index for measuring outcomes after sacroiliac joint fusion, as this article was simply an evaluation of ODI as an outcome measure. ${ }^{182}$ 